\title{
Barrier Capability of Skin Lipid Models: Effect of Ceramides and Free Fatty Acid Composition
}

Uche, L.E.; Gooris, G.S.; Bouwstra, J.A.; Beddoes, C.M.

\section{Citation}

Uche, L. E., Gooris, G. S., Bouwstra, J. A., \& Beddoes, C. M. (2019). Barrier Capability of Skin Lipid Models: Effect of Ceramides and Free Fatty Acid Composition. Langmuir, 35(47), 15376-15388. doi:10.1021/acs.langmuir.9b03029

Version: $\quad$ Publisher's Version

License: $\quad$ Licensed under Article 25fa Copyright Act/Law (Amendment Taverne)

Downloaded from: https://hdl.handle.net/1887/3199136

Note: To cite this publication please use the final published version (if applicable). 


\title{
Barrier Capability of Skin Lipid Models: Effect of Ceramides and Free Fatty Acid Composition
}

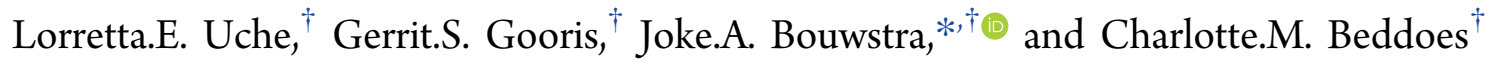 \\ ${ }^{\dagger}$ Division BioTherapeutics, Leiden Academic Centre for Drug Research, Leiden University, 2333 CC Leiden, Netherlands
}

ABSTRACT: The skin is an effective barrier that prevents the influx of harmful substances from the environment and the efflux of body fluid. This barrier function is ascribed to the intercellular lipids present in the outermost layer of the skin referred to as the stratum corneum (SC). These lipids are composed mainly of ceramides (CERs), cholesterol, and free fatty acids (FFAs). Alterations in the SC lipid composition and barrier function impairment occur in several skin diseases including atopic dermatitis $(\mathrm{AD})$. As the etiology of $\mathrm{AD}$ is multifactorial, establishing the relationship between the changes in SC lipid composition and barrier function impairment in the patients remains a challenge. Here, we employed model membrane systems to investigate the contribution of various anomalies in the SC CER and FFA composition observed in AD patients' skin to the barrier dysfunction. Using ethyl-p-aminobenzoate permeation and transepidermal water loss values as markers for barrier function, we determined that the alterations in SC lipid composition contribute to the impaired barrier function in $\mathrm{AD}$ patients. By the use of biophysical techniques, we established that the largest reduction in barrier capability was observed in the model with an increased fraction of short-chain FFAs, evident by the decrease in chain packing density. Modulations in the CER subclass composition impacted the lamellar organization while having a smaller effect on the barrier function. These findings provide evidence that $\mathrm{AD}$ therapies normalizing the FFA composition are at least as important as normalizing CER composition.

\section{INTRODUCTION}

Lipids can act as structural components for cell membranes but are also important for signaling and energy storage. ${ }^{1-6}$ In most viable cell membranes, the most important components are phospholipids, sphingolipids, and cholesterol (CHOL). A special group of sphingolipids is the ceramides (CERs). In the outermost layer of the epidermis, the stratum corneum (SC), these CERs together with cholesterol and free fatty acids (FFAs) are the most important components of the lipid matrix, a structure that is crucial in maintaining the skin barrier function. ${ }^{7}$ A major difference between the SC lipid composition and other biological membranes is that the former is basically devoid of phospholipids. The SC lipid matrix surrounds the individual keratin-filled terminally differentiated cells, the corneocytes. The SC structure has been described as being analogous to bricks and mortar structure, the corneocyte being the bricks and the intercellular lipids the mortar. ${ }^{8}$ X-ray diffraction studies have revealed that the intercellular lipids are assembled in two coexisting lamellar phases with periodicities of $\sim 13 \mathrm{~nm}$ and $\sim 6 \mathrm{~nm}$ known as the long and short periodicity phases (LPP and SPP), respectively. ${ }^{9,10}$ Within the lamellae, the majority of the SC lipids preferably adopt a dense orthorhombic lateral packing at skin temperature $\left(30-32{ }^{\circ} \mathrm{C}\right)$, while a portion of the lipids adopt the less dense hexagonal packing. ${ }^{11,12}$ This is distinctive from most biological cell membranes, which often form a liquid (ordered) phase. The ordered lipid packing in SC is induced by (i) the FFAs with predominantly saturated chains, with carbon chain lengths ranging between 12 and 30, the majority of the FFA having a chain length of 22, 24, or 26 carbon atoms $^{13,14}$ and (ii) the CERs with a small headgroup and long hydrocarbon tails. The CERs can vary in the headgroup structure and chain length. Currently, 18 subclasses of CERs have been identified in the human SC. ${ }^{15-17}$ The commonly adopted nomenclature for CER is based on Motta et al., ${ }^{18}$ in which the CERs are designated with 2-3 letters, defining the type of sphingoid base and linked fatty acid acyl chain (Figure 1).

Alterations in the SC lipid composition has been reported in one of the most prevalent, chronic inflammatory skin disease referred to as atopic dermatitis $(\mathrm{AD})$. In industrialized nations, the incidence of $\mathrm{AD}$ has increased to about $15-30 \%$ in children, and $2-10 \%$ in adults. The etiology of $\mathrm{AD}$ is multifactorial, involving the interaction of immunological, genetic, and environmental factors. ${ }^{19}$ A compromised skin barrier, indicated by increased water transport across the SC, is characteristic of patients with $\mathrm{AD} .^{20,21}$ Several studies have reported that the reduced skin barrier function is associated with changes in the lipid composition. The following changes in lipid composition were described in $\mathrm{AD}$ patients' skin

Received: September 26, 2019

Revised: November 7, 2019

Published: November 7, 2019 

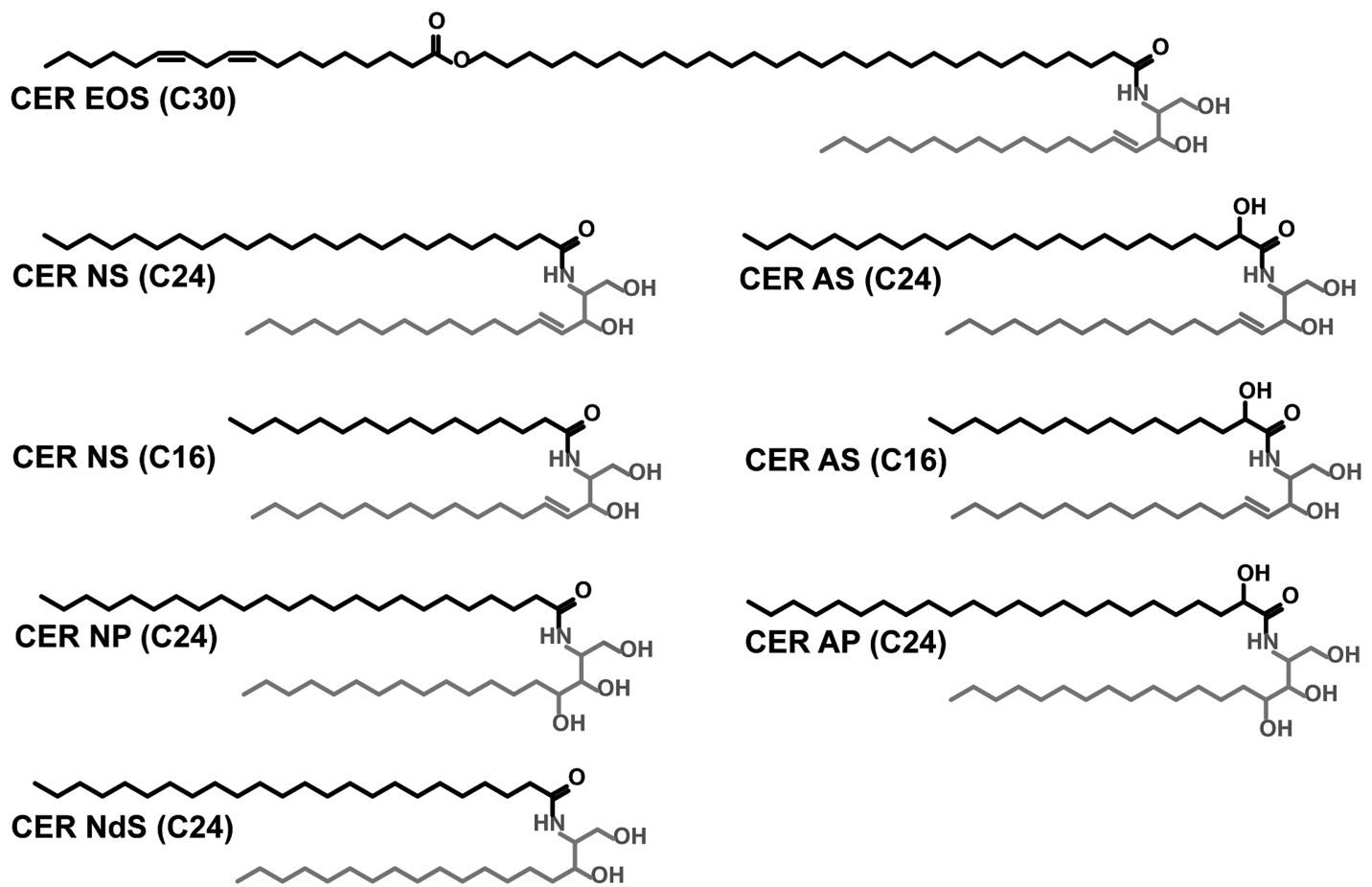

Figure 1. Molecular structure of the CERs used in the study. CERs consist of a sphingoid base (marked in gray) linked to a fatty acid acyl chain (marked in black) via an amide bond. The fatty acid acyl chain is either nonhydroxylated [N], $\alpha$-hydroxylated [A], or $\omega$-esterified [EO], while the sphingoid base is either sphingosine $[\mathrm{S}]$ or phytosphingosine $[\mathrm{P}]$.

compared to healthy skin: (i) a reduction in the levels of CER NP, CER NH, CER EO classes, while CER NS and AS were increased, $^{22-25}$ (ii) a reduction in chain length of FFAs ${ }^{26}$ and CERs, specifically increased level of CERs AS and NS (C16) with a total chain length of 34 carbon atoms. ${ }^{22,25}$ As these changes in lipid composition occur simultaneously, ${ }^{20,27,28}$ it is not yet established which of them is the underlying factor of the impaired skin barrier.

In the current study, we investigated in a systematic way which changes in SC lipid composition reported in $\mathrm{AD}$ patients resulted in the most dramatic changes in the lipid organization, thereby possibly increasing the lipid barrier dysfunctionality. A healthy skin model based on the SC lipid composition and diseased skin models that mimicked different aspects of the altered lipid composition in atopic dermatitis patients' skin were developed. We showed that an increased level of short-chain FFAs resulted in a more drastic reduction in barrier function than compositional changes of the CERs. Knowledge from this study could aid in the design of rational therapy for the treatment of inflammatory skin diseases in which compositional changes in SC lipids are implicated.

\section{EXPERIMENTAL SECTION}

2.1. Materials. The synthetic CERs: $N$-(tetracosanoyl)-sphingosine (CER NS), $\mathrm{N}$-(tetracosanoyl)-phytosphingosine (CER NP), $\mathrm{N}$ (2R-hydroxy-tetracosanoyl)-sphingosine (CER AS), N-(2R-hydroxytetracosanoyl)-phytosphingosine (CER AP) of acyl carbon chain length $\mathrm{C} 24$, and $\mathrm{N}$-(30-linoleoyloxy-triacontanoyl)-sphingosine (EOS C30) used in this study were generously donated by Evonik (Essen, Germany). CERs NS and AS C16 and N-(tetracosanoyl)dihydrosphingosine (CER NdS C24) were purchased from Avanti. The CERs were of $\geq 90 \%$ purity. The FFAs, ethyl- $p$-aminobenzoate (E-PABA), CHOL, and acetate buffer salts were acquired from SigmaAldrich Chemie GmbH (Schnelldorf, Germany). The perdeuterated FFAs (DFFAs) with chain lengths of $\mathrm{C} 18$ and $\mathrm{C} 20$ were obtained from Cambridge Isotope Laboratories (Andover, Massachusetts). The DFFAs with chain lengths of $\mathrm{C} 16$ and $\mathrm{C} 22$ were purchased from Larodan (Malmö, Sweden). The DFFA with a chain length of C24 was obtained from Arc Laboratories B.V. (Apeldoorn, The Netherlands). All organic solvents were procured from Labscan Ltd. (Dublin, Ireland). All other reagents were of analytical grade and used without further purification. The water was Millipore quality, obtained through a Milli-Q Integral Water Purification System (Millipore, Bedford, MA). Nucleopore polycarbonate filter disks (pore size 0.05 $\mu \mathrm{m}$ ) were acquired from Whatman (Kent, UK).

2.2. Isolation of SC from Native Skin. SC was isolated from abdominal or mammary skin, which was obtained within $24 \mathrm{~h}$ after cosmetic surgery. The skin surface was first cleaned with $70 \%$ ethanol and Milli-Q water thereafter. The skin was dermatomed to a thickness of $\sim 0.6 \mathrm{~mm}$. The SC was separated from the epidermis by trypsin digestion; $0.1 \%$ in phosphate-buffered saline (PBS $0.1 \mathrm{M}$ solution: $\mathrm{NaCl}, \mathrm{Na}_{2} \mathrm{HPO}_{4}, \mathrm{KH}_{2} \mathrm{PO}_{4}$, and $\mathrm{KCl}$ in milli-Q water with a concentration of $8.13,1.14,0.20$, and $0.19 \mathrm{~g} / \mathrm{L}$, respectively, at $\mathrm{pH}$ 7.4) after overnight incubation at $4{ }^{\circ} \mathrm{C}$ and subsequently at $37{ }^{\circ} \mathrm{C}$ for $1 \mathrm{~h}$. The SC was then placed in a $0.1 \%$ solution of trypsin inhibitor, rinsed twice with Milli-Q water and allowed to dry. The SC was stored in a silica-containing, opaque, sealed box, under nitrogen in order to prevent oxidation of the intercellular SC lipids.

2.3. Preparation of the Model Lipid Mixtures. Five SC lipid models (healthy and diseased skin) were prepared as equimolar mixtures of CER, CHOL, and FFAs. The lipid composition of the healthy skin model (denoted as Healthy) was based on the native SC lipid composition. ${ }^{15,29}$ The most prevalent CERs in human skin were included in the model, except for CERs comprised of a 6-hydroxy sphingoid bases that were not available. As CER EOS constitutes over $50 \%$ of the total CER EO class present in the human CER, ${ }^{15}$ it represented the CER EO in the healthy skin model. To prepare the diseased skin models, the lipid composition of the healthy skin model was adjusted to mimic various aberrations reported in the skin of $\mathrm{AD}$ patients. The changes made were (i) replacing a fraction of CER NS (C24) and CER AS (C24) with by CER NS (C16) and CER AS (C16), respectively, denoted as Dis-CER $\mathrm{Ch}_{\text {ch }}$ (ii) besides the presence of CERs NS and AS (C16), a reduction of the level of CER EOS and 
Table 1. CER Composition of the Various Models Used in the Study

\begin{tabular}{|c|c|c|c|c|c|c|c|}
\hline \multirow[b]{2}{*}{ CER name and chain length } & \multicolumn{7}{|c|}{ Model name \& CER molar ratio (\%) } \\
\hline & Healthy & Dis-CER $_{\mathrm{ch}}$ & Dis-CER ${ }_{\text {ch-D-NS (C24) }}$ & Dis-CER ${ }_{\text {ch-D-NS (C16) }}$ & Dis-CER ${ }_{\text {ch-SbC }}$ & Dis-FFA $_{\text {ch }}$ & Dis-Combi \\
\hline CER EOS (C30) & 15 & 15 & 15 & 15 & 7 & 15 & 7 \\
\hline CER NdS (C24) & 13 & 13 & 13 & 13 & 13 & 13 & 13 \\
\hline CER NS (C24) & 13 & 6.5 & & 6.5 & 12 & 13 & 12 \\
\hline D-CER NS (C24) & & & 6.5 & & & & \\
\hline CER NS (C16) & & 6.5 & 6.5 & & 12 & & 12 \\
\hline D-CER NS (C16) & & & & 6.5 & & & \\
\hline CER NP (C24) & 30 & 30 & 30 & 30 & 16 & 30 & 16 \\
\hline CER AS (C24) & 13 & 6.5 & 6.5 & 6.5 & 12 & 13 & 12 \\
\hline CER AS (C16) & & 6.5 & 6.5 & 6.5 & 12 & & 12 \\
\hline CER AP $(\mathrm{C} 24)^{a}$ & 16 & 16 & 16 & 16 & 16 & 16 & 16 \\
\hline Total & 100 & 100 & 100 & 100 & 100 & 100 & 100 \\
\hline
\end{tabular}

${ }^{a}$ In our study, we used the native D-isomer of CER AP and CER AS which unlike the unnatural L-isomer has been shown to display native like behavior. ${ }^{30}$

NP subclasses was included, counterbalanced by an increase in the levels of CER NS and AS subclasses, referred to as Dis-CER $\mathrm{Ch-SbC}_{\text {; }}$ (iii) an increased fraction of short-chain FFAs referred to as Dis-FFA $A_{c h}$, and (iv) a combination of all the changes in CERs \& FFAs referred to as Dis-Combi. The CERs and FFAs composition of the models are presented in Tables 1 and 2, respectively. Additional models were

Table 2. FFA Composition of the Various Models Used in the Study

\begin{tabular}{|c|c|c|c|}
\hline \multirow[b]{2}{*}{$\begin{array}{c}\text { FFA name and chain } \\
\text { length }\end{array}$} & \multicolumn{3}{|c|}{ Model name \& FFA molar ratio (\%) } \\
\hline & Healthy & $\begin{array}{l}\text { Dis-CER } \text { chh }_{\text {ch }} / \text { Dis- } \\
\text { CER }_{\text {ch-SbC }}\end{array}$ & $\begin{array}{c}\text { Dis-FFA } \text { ch/ }_{\text {combis- }} \text { Dis- } \\
\text { combi }\end{array}$ \\
\hline Palmitic Acid (C16) & 1.8 & 1.8 & 26 \\
\hline Stearic Acid (C18) & 4.0 & 4.0 & 19 \\
\hline Arachidic Acid (C20) & 7.6 & 7.6 & 10 \\
\hline Behenic Acid (C22) & 47.8 & 47.8 & 21 \\
\hline Lignoceric Acid (C24) & 38.8 & 38.8 & 24 \\
\hline Total & 100 & 100 & 100 \\
\hline
\end{tabular}

prepared in which FFAs were replaced by their deuterated counterparts. The resulting models are denoted by $\mathrm{D}$ - before the

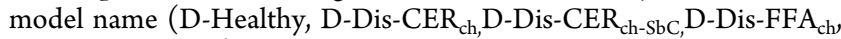
and D-Dis-Combi). Other models were prepared in which either CER NS (C24) or CER NS (C16) fatty acid acyl chain in the Dis-CER ch $_{\text {}}$ model was substituted by its deuterated counterpart (D-CER NS

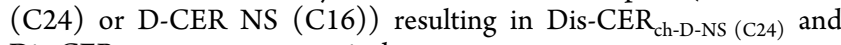

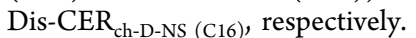

2.4. Preparation of SC Model Membranes for Permeability Studies and Transepidermal Water Loss (TEWL) Measurements. To prepare the SC model membranes, $0.9 \mathrm{mg}$ of the appropriate lipid composition was dissolved in $200 \mu \mathrm{L}$ of a hexane/ ethanol (2:1) solution. The solution was sprayed over an area of $10 \times$ $10 \mathrm{~mm}$, on a nucleopore polycarbonate filter disk with $0.05 \mu \mathrm{m}$ pore size (Whatman, Kent, UK), using a Linomat IV device with an extended $y$-axis arm (Camag, Muttenz, Switzerland) under a gentle stream of nitrogen. The solution was sprayed at $14 \mu \mathrm{L} / \mathrm{sec}$ at an approximate distance of $1 \mathrm{~mm}$ between the nozzle and the spraying surface. The samples were equilibrated for $10 \mathrm{~min}$ at $85^{\circ} \mathrm{C}$, which was sufficient to ensure that the lipid mixtures had fully melted and then gradually cooled to room temperature. The heating and cooling cycle was repeated once more.

2.5. Permeability Studies. The permeation studies were performed using Permegear in-line diffusion cells (Bethlehem PA, U.S.A.) with a diffusion area of $0.28 \mathrm{~cm}^{2}$. The sprayed membranes in various lipid compositions were mounted in the diffusion cells and hydrated for $1 \mathrm{~h}$ with the acceptor phase consisting of PBS at $\mathrm{pH} 7.4$ prior to the experiment. Before use, the PBS was filtered and degassed for $30 \mathrm{~min}$ under a vacuum to remove any dissolved air. The donor phase was a saturated E-PABA solution $(0.65 \mathrm{mg} / \mathrm{mL})$ in $\mathrm{pH} 5$ acetate buffer, The solution was stirred with a magnetic stirrer, perfused at a flow rate of about $2 \mathrm{~mL} / \mathrm{h}$ and degassed continuously by an online degasser. The experiment was performed under occlusive conditions by closing the opening of the donor compartment with an adhesive tape. The temperature of the membranes was maintained at $32{ }^{\circ} \mathrm{C}$ mimicking the skin temperature. The acceptor fluid was collected over $15 \mathrm{~h}$ at $1 \mathrm{~h}$ intervals. At the end of the diffusion study, the volume per collected fraction of PBS was determined by weight and the concentration of E-PABA was determined by UPLC. Permeation of multiple samples of each model was analyzed, $n \geq 6$. The steady-state flux values were calculated from the plots of E-PABA flux values versus time, at a time interval between the fifth and 15th $\mathrm{h}$.

2.6. Ultra High Performance Liquid Chromatography (UPLC). The analysis of E-PABA was undertaken with Acquity UPLC systems (Waters Co., Milford, MA, U.S.A.). The UPLC systems consisted of a quaternary solvent manager (a high-pressure pump), a tunable ultraviolet/visible absorbance detector, and a sample manager. UPLC special analytical column packed with $1.7 \mu \mathrm{m}$, bridged, ethyl siloxane, hybrid particles, was used as the stationary phase. The column temperature was set at $40^{\circ} \mathrm{C}$. The mobile phase was composed of mixtures of $0.1 \%$ trifluoroacetic acid in acetonitrile/ milli-Q water at a 40:60 (v/v) ratio. The flow rate of the mobile phase was set at $1 \mathrm{~mL} / \mathrm{min}$. A $10 \mu \mathrm{L}$ of the sample was injected on the column. The detector wavelength was set at $286 \mathrm{~nm}$. Data were collected and processed by MassLynx and TargetLynx software V4.1 SCN951 (Waters Co., Milford, U.S.A.).

A $0.5 \mathrm{mg} / \mathrm{mL}$ E-PABA stock solution in a 1:1 solution of methanol and milli- $\mathrm{Q}$ water was prepared. Eight different concentrations were prepared by serial dilutions of the stock solution with milli- $Q$ water to plot the standard curve. The linearity of the relationship was evaluated in a concentration range of $0.1-10 \mu \mathrm{g} / \mathrm{mL}$ covering the range of concentrations obtained when analyzing the concentration of E-PABA permeating the model membranes. The calibration curves were obtained using least-squares linear regression and the linearity was confirmed with the $\mathrm{R}^{2}$ values. The UPLC method was previously validated for E-PABA analysis as per ICH (International conference on harmonization) guidelines with respect to linearity, precision, limit of detection (LOD), and limit of quantification (LOQ),. ${ }^{31-33}$

2.7. TEWL Measurements. An AquaFlux (AF200, Biox Systems Ltd., London, UK) was used to measure TEWL of the lipid models. The measurement has been previously described elsewhere. ${ }^{34}$ Briefly, the sprayed membranes were mounted in a diffusion cell. The TEWL device was then coupled vertically with the donor compartment of the diffusion cell using a special measurement cap (Biox systems Limited, UK) in order to seal the compartment and ensure vapor tight connectivity. The TEWL values for the models studied were recorded over a period of $30 \mathrm{~min}$, after which an average reading during the final $10 \mathrm{~min}$ of the measurement was calculated, $n=7$. 

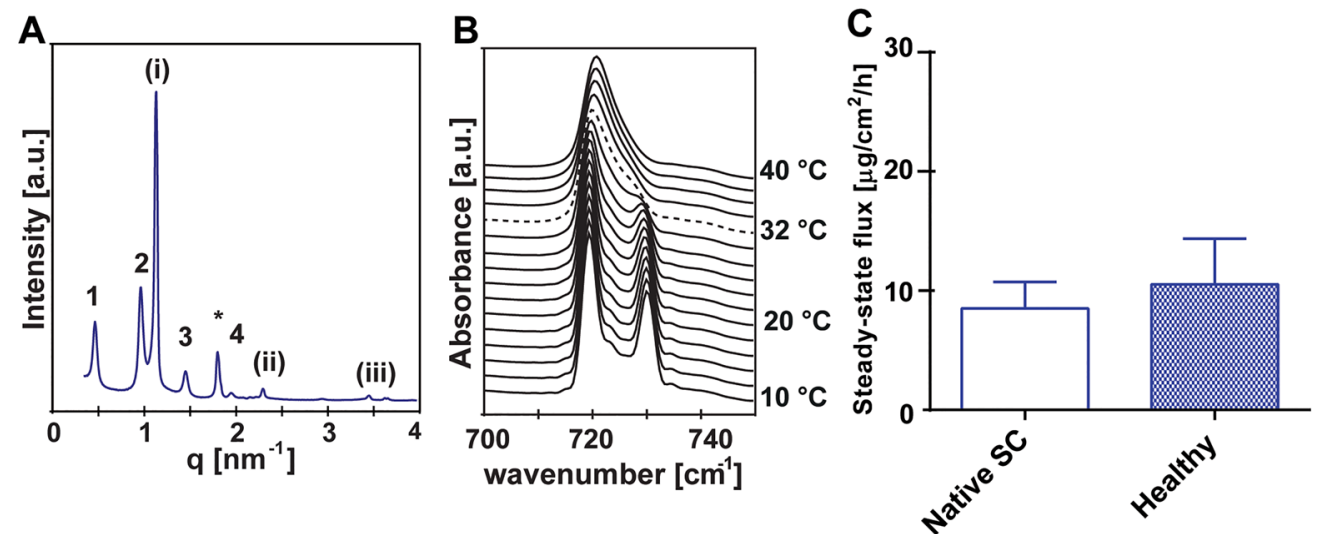

Figure 2. Characterization of the healthy skin model. (A) SAXD profile at $25{ }^{\circ} \mathrm{C}$. The arabic numbers $(1,2,3,4)$ indicate the diffraction orders of the LPP, $d=12.8$ positioned at $q=0.49,0.98,1.46$, and $1.96 \mathrm{~nm}^{-1}$. The roman numbers (i, ii, iii) indicate the diffraction orders of the SPP, $d=5.4$ positioned at $q=1.16,2.3$, and $3.48 \mathrm{~nm}^{-1}$. (B) The thermotropic response of the $\rho \mathrm{CH}_{2}$ modes. The presence of two peaks positioned at $\sim 720$ and $730 \mathrm{~cm}^{-1}$ indicate orthorhombic lateral packing while a single peak at $\sim 720 \mathrm{~cm}^{-1}$ indicates hexagonal lateral packing. (C) The average steady-state flux of E-PABA across the native SC and healthy skin model $(5-15 \mathrm{~h})$. Data presented as the mean $\pm \mathrm{SD}, n \geq 6$, significance level $(P<0.05)$.

2.8. Sample Preparation for FTIR and X-ray Diffraction Studies. The appropriate lipid composition was dissolved in chloroform/methanol $(2: 1)$ to a concentration of $5 \mathrm{mg} / \mathrm{mL}$. Either $1.5 \mathrm{mg}$ was sprayed over an area of $10 \times 10 \mathrm{~mm}$ on an $\mathrm{AgBr}$ window (for FTIR studies) or $1 \mathrm{mg}$ was sprayed over an area of $2 \times 4 \mathrm{~mm}$ on mica (for X-ray diffraction studies) using a Linomat IV device (Camag, Muttenz, Switzerland) with an extended $y$-axis arm and equilibrated as described earlier (see Preparation of the Model Lipid Mixtures). The samples were equilibrated for $10 \mathrm{~min}$ at $85{ }^{\circ} \mathrm{C}$. The heating and cooling cycle was repeated once more. Finally, the samples were hydrated in deuterated acetate buffer ( $\mathrm{pH}$ 5.0) and incubated at $37^{\circ} \mathrm{C}$ for at least $15 \mathrm{~h}$ prior to measurements to ensure that the samples were fully hydrated.

2.9. FTIR Measurements. FTIR measurements were implemented with a Varian 670-IR spectrometer (Agilent Technologies, Inc., Santa Clara, CA) equipped with a broad-band mercury cadmium telluride detector, cooled by liquid nitrogen. The samples were purged continuously under dry air, starting $30 \mathrm{~min}$ prior to data acquisition. The spectra were collected in transmission mode and acquired by the coaddition of $256 \mathrm{scans}$ at $1 \mathrm{~cm}^{-1}$ resolution, over $4 \mathrm{~min}$. In order to examine the thermotropic phase behavior, the sample was measured between 0 and $100{ }^{\circ} \mathrm{C}$ at a heating rate of $0.25{ }^{\circ} \mathrm{C} / \mathrm{min}$, resulting in a $1{ }^{\circ} \mathrm{C}$ temperature rise per recorded spectrum. The spectra were deconvoluted using a half-width of $4 \mathrm{~cm}^{-1}$ and an enhancement factor of 1.7. The software used was Agilent resolution pro (Agilent Technologies, Palo Alto CA, U.S.A.). Samples were measured over a range of $600-4000 \mathrm{~cm}^{-1}$. The $\mathrm{CH}_{2}$ symmetric stretching modes (2845-2855 $\mathrm{cm}^{-1}$ ) and $\mathrm{CD}_{2}$ symmetric stretching modes (2080$2100 \mathrm{~cm}^{-1}$ ), referred to as $\nu_{\mathrm{s}} \mathrm{CH}_{2}$ and $\nu_{\mathrm{s}} \mathrm{CD}_{2}$ modes, respectively, were chosen to examine the conformational ordering and phase transition of the lipid chains. The conformational ordering was determined at $10{ }^{\circ} \mathrm{C}$, which was prior to the orthorhombic to hexagonal phase transition. The linear regression curve fitting method was used to determine the midtransition temperature described previously. ${ }^{35}$ The $\mathrm{CH}_{2}$ rocking vibration mode $\left(719-730 \mathrm{~cm}^{-1}\right)$ and scissoring mode $\left(1462-1473 \mathrm{~cm}^{-1}\right)$ referred to as $\rho \mathrm{CH}_{2}$ and $\delta \mathrm{CH}_{2}$, respectively, were evaluated to monitor the lateral packing, while the $\mathrm{CD}_{2}$ scissoring modes $\left(1085-1095 \mathrm{~cm}^{-1}\right)$ were examined for the determination of the mixing properties of the lipid chains. Multiple samples were measured for each condition, $n \geq 2$.

2.10. X-ray Diffraction Studies. The small- and wide-angle X-ray diffraction (SAXD and WAXD) diffraction measurements were performed at the European Synchrotron Radiation Facility (ESRF, Grenoble) at station BM26B. SAXD images were collected using a Pilatus $1 \mathrm{M}$ detector with $981 \times 1043$ pixels of $172 \mu \mathrm{m}$ spatial resolution, while the WAXD patterns were collected using a $300 \mathrm{~K}$ Pilatus detector with $1475 \times 195$ pixels of $172 \mu \mathrm{m}$ spatial resolution.
The SAXD detector was calibrated using silver behenate, while the WAXD detector was calibrated using the two strongest reflections of high-density polyethylene (HDPE). The X-ray wavelength was set at $0.1033 \mathrm{~nm}$. The sample-to-detector distances were 1.98 and $0.31 \mathrm{~m}$ for SAXD and WAXD, respectively. The samples were hydrated for 24 $\mathrm{h}$ in milli- $\mathrm{Q}$ water prior to mounting in parallel to the primary beam in a sample holder with temperature controlled at $25{ }^{\circ} \mathrm{C}$. The diffraction patterns of the samples were acquired in two positions. At each position, the samples were measured for $90 \mathrm{~s}$. The scattering intensity $(I)$ was measured as a function of the scattering vector $(q)$. The latter is defined as $q=(4 \pi \sin \theta) / \lambda$, where $\theta$ is the scattering angle and $\lambda$ is the wavelength. From the positions of a series of equidistant peaks $\left(q_{n}\right)$, the periodicity of a lamellar phase was calculated using the equation $d=2 \mathrm{n} \pi / q_{n}$ in which $n$ is the order of the diffraction peak. The one-dimensional intensity profiles used in these calculations were obtained by the reduction of the 2D SAXD pattern from Cartesian $(x, y)$ to polar $(\rho, \theta)$ coordinates and integration over an $\theta$ range. WAXD was used to obtain the diffraction patterns related to the lateral packing of lipids. The diffraction pattern was subsequently collected between 25 and $85{ }^{\circ} \mathrm{C}$ in order to examine the temperature-induced phase changes in various models. Each sample condition was measured, $n \geq 2$.

2.11. Data Analysis. Unpaired $t$ test was performed for analysis of the permeability studies data for the healthy skin model versus native skin. One-way ANOVA with Dunnett's multiple comparison test was performed to analyze the permeability studies' and FTIR data for the healthy against the diseased skin models. The significance level for rejection of null hypothesis was set at $P<0.05(*), P<0.01(* *), P<$ $0.001(* * *)$, and $P<0.0001(* * * *)$.

\section{RESULTS}

3.1. Healthy Skin Model Membrane Properties Mimic That of Human SC. First, we determined whether the lipid properties of the healthy skin model membrane mimic those of human SC. The lamellar and lateral lipid organization of the healthy skin model were characterized by SAXD and FTIR, respectively. The SAXD profile exhibits two lamellar phases with repeat distances of 12.8 and $5.4 \mathrm{~nm}$ corresponding to the LPP and SPP in the native human SC, respectively ${ }^{9,10}$ (Figure $2 A)$. With respect to the lateral lipid organization, the thermotropic response of the $\rho \mathrm{CH}_{2}$ mode is provided in Figure 2B. The $\rho \mathrm{CH}_{2}$ contour is split into two peaks positioned at $\sim 720$ and $730 \mathrm{~cm}^{-1}$. The splitting is a result of the short-range coupling of adjacent $\rho \mathrm{CH}_{2}$ modes and occurs only in a phase possessing orthorhombic packed chains, as 

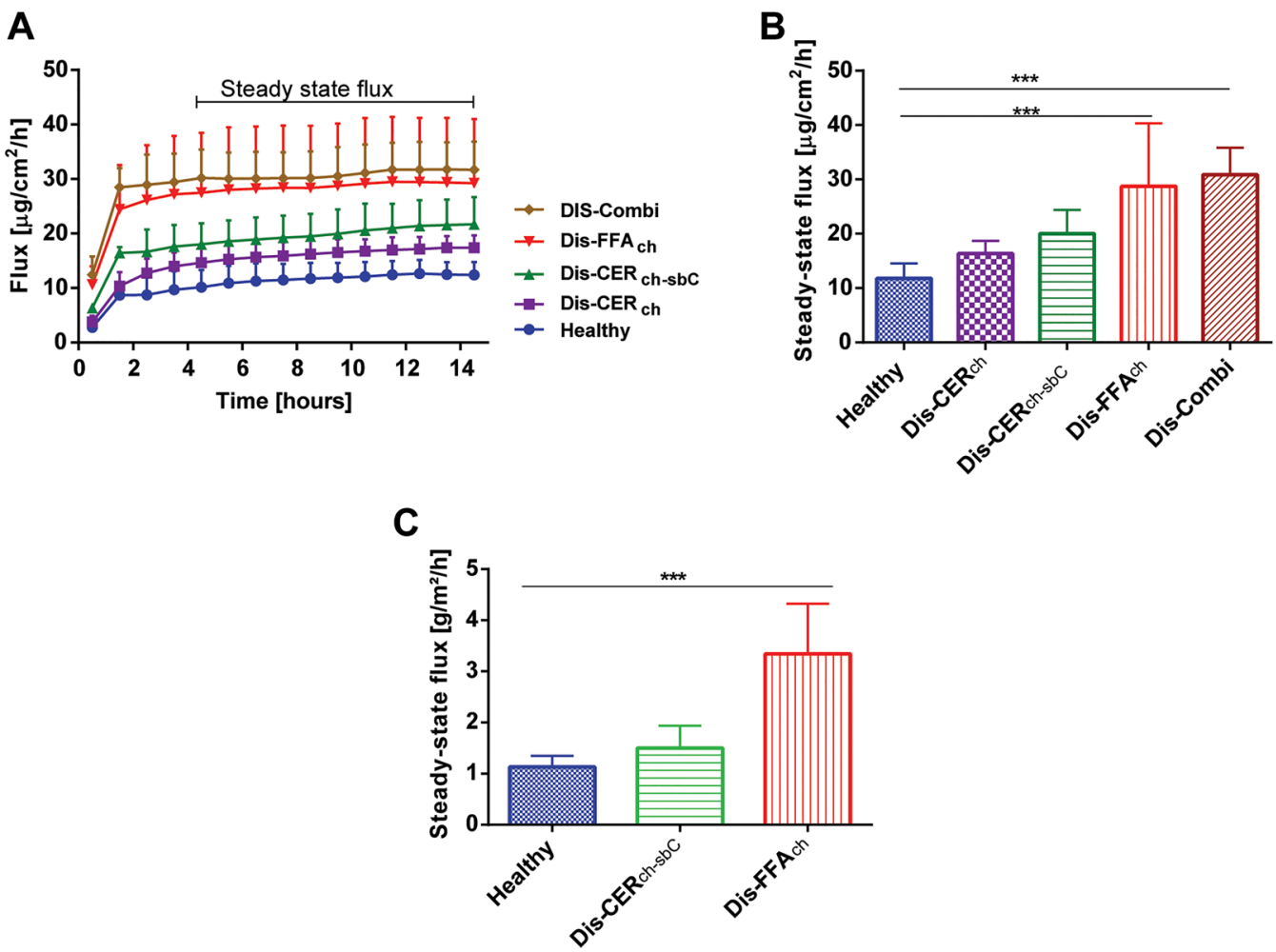

Figure 3. Permeability of the model membranes. (A) The flux of E-PABA across the model membranes over $15 \mathrm{~h}$. (B) The average steady-state flux of E-PABA across the model membranes $(5-15 \mathrm{~h})$. Data presented as the means $\pm \mathrm{SD}, n \geq 6$. E-PABA steady-state flux was significantly higher in the models containing an increased level of short-chain FFAs compared to the healthy skin model, $* * *(P<0.001)$. (C) TEWL across the model membranes, with Dis $\mathrm{FFA}_{\mathrm{ch}}$ showing significantly higher permeability compared to the healthy skin model, $n=7, * * * P<0.001$.

observed in human SC. ${ }^{36}$ As the temperature increases, the $730 \mathrm{~cm}^{-1}$ peak, which is attributed exclusively to the orthorhombic phase reduces in intensity, implying a loss in orthorhombic packing within the lipid population. At $32{ }^{\circ} \mathrm{C}$, the peak appears as a weak shoulder, indicating a significant reduction in the proportion of lipids adopting an orthorhombic packing, and finally disappears at $36^{\circ} \mathrm{C}$, signaling a complete orthorhombic to hexagonal phase transition of the lipids. The permeation of E-PABA through the native human SC and healthy skin model membrane were compared. The E-PABA steady-state flux is presented (Figure 2C). There is no significant difference in permeability between the native SC and the healthy skin model membrane. As the healthy skin model membrane properties are sufficiently similar to those of the lipid matrix in human SC, the composition of the membrane was modulated to mimic several aspects of the lipid composition in SC of AD.

3.2. Changes in Lipid Composition Resulted in Increased Permeability in AD Patients' Skin Models. In order to examine whether the changes in the lipid composition affect the lipid barrier function, the permeability of the healthy and diseased model membranes was monitored. The average fluxes of E-PABA across the models are displayed in Figure 3A. The E-PABA's average steady-state flux values are plotted in Figure 3B. The highest E-PABA steady-state flux was observed in Dis-combi, where the alterations in the CER and FFA composition were combined. The flux was significantly higher compared to that of the healthy skin model. To determine which change in composition contributed the most to the reduced SC lipid barrier, the contribution of each of the anomalies in the CER and FFA composition on permeability was examined. First, the CER composition was examined. The replacement of $50 \%$ of the CER NS and CER AS (C24) by CER NS and CER AS (C16), respectively, (model Dis-CER ch $_{\text {) }}$ resulted in a slight but not significant increase in E-PABA flux compared to the healthy skin model. In the next step, the total CERs NS and AS (C24) fractions were increased, of which $50 \%$ were the C16 counterparts, while CERs NP and EOS were reduced. This resulted in a further increase (not statistically significant) in permeability. In contrast, when focusing on the FFA composition, the E-PABA steady-state flux across Dis-FFA ${ }_{c h}$, which contains increased levels of shortchain FFAs, was significantly higher than that across the healthy skin model.

3.3. Changes in Lipid Composition Resulted in Increased TEWL in AD Patients' Skin Models. TEWL is often monitored to measure the inside-out skin barrier function in clinical studies. For this reason, TEWL was also used to detect whether selected changes in CERs and FFAs compositions resulted in an increased TEWL indicating a reduced lipid barrier. The TEWL values of Healthy, DIS- ${ }_{\text {CERch-sbC, }}$ and Dis FFA $_{\text {ch }}$ are plotted in Figure 3C. The diseased model membranes show higher TEWL values than the healthy skin model indicating reduced barrier capability. The TEWL value of DIS-CER $\mathrm{ch}_{\text {sbC }}$ was 1.2 times higher than that of the healthy skin model and not statistically significant. In contrast, DIS-FFA ${ }_{\text {ch }}$ resulted in significantly higher TEWL values, exceeding that of the healthy skin model by 2.8 times. This finding is consistent with the results of the E-PABA permeation study.

3.4. Increased Level of Short-Chain FFAs Resulted in Lower Conformational Ordering and Significantly 

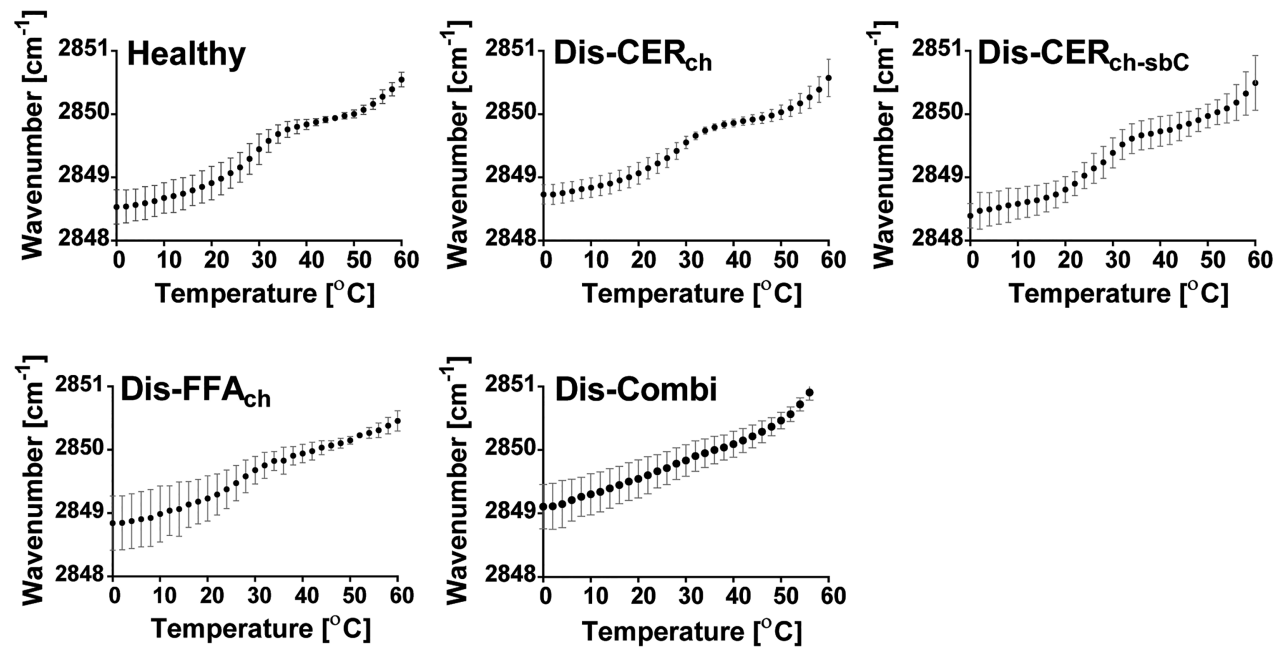

Figure 4. Thermotropic response of the $\nu_{\mathrm{s}} \mathrm{CH}_{2}$ modes of the lipid models. The $\nu_{\mathrm{s}} \mathrm{CH}_{2}$ modes of all models showing frequencies between 0 and 60 ${ }^{\circ} \mathrm{C}$. The wavenumber at $10{ }^{\circ} \mathrm{C}$ is higher in the Dis-FFA $A_{\text {ch }}$ and Dis-Combi compared to the healthy skin model indicating the highest conformational ordering in the latter. The midpoint temperature of the OR-HEX phase transition is significantly lower in Dis-FFA $\mathrm{A}_{\mathrm{ch}}$ compared to the healthy skin model while the transition is undefined in Dis-Combi. Data presented as the means $\pm \mathrm{SD}, n \geq 3$.

Table 3. E-PABA Steady-State Flux Across the Model Membranes with Their SD, the Wavenumber at $10{ }^{\circ} \mathrm{C}$, and Midpoint Temperatures of the Orthorhombic-Hexagonal Phase Transition $\left(T_{M, O R-H E X}\right)$ in Mixtures with Protiated CERs and FFA Chains and the Ordered to Disordered Phase Transition $\left(T_{M, H E X-L I Q}\right)$ of the $\nu_{s} \mathrm{CH}_{2}$ Mode and $\nu_{s} \mathrm{CD}_{2}$ Mode in Mixtures with Protiated CER Chains and Deuterated FFA Chains

\begin{tabular}{lccccc}
\multicolumn{1}{c}{ Lipid model } & Steady-state flux $\left(\mu \mathrm{g} / \mathrm{cm}^{2} / \mathrm{h}\right)$ & Wavenumber $\left(\mathrm{cm}^{-1}\right)$ & $T_{\mathrm{M}, \text { OR-HEX }}\left({ }^{\circ} \mathrm{C}\right)$ & $\nu_{\mathrm{s}} \mathrm{CH}_{2}$ mode $T_{\mathrm{M}, \text { HEX-LIQ }}\left({ }^{\circ} \mathrm{C}\right)$ & $\nu_{\mathrm{s}} \mathrm{CD} \mathrm{D}_{2}$ mode $T_{\mathrm{M}, \mathrm{HEX}-\mathrm{LIQ}}\left({ }^{\circ} \mathrm{C}\right)$ \\
(D-)Healthy & $11.8 \pm 2.7$ & $2848.7 \pm 0.2$ & $28.0 \pm 1.7$ & $67.1 \pm 1.5$ & $66.9 \pm 2.5$ \\
(D-)Dis-CER & $16.4 \pm 2.3$ & $2848.8 \pm 0.2$ & $27.1 \pm 0.8$ & $65.9 \pm 1.4$ & $64.9 \pm 2.5$ \\
(D-)Dis-CER & $20.0 \pm 3.6$ & $2848.6 \pm 0.2$ & $27.6 \pm 0.9$ & $63.1 \pm 2.4$ & $62.2 \pm 1.7$ \\
$(\mathrm{D}-)$ Dis-FFC & $28.7 \pm 11.6$ & $2849.0 \pm 0.4$ & $24.9 \pm 1.3$ & $62.8 \pm 0.7$ & $63.7 \pm 0.2$ \\
(D-)Dis-Combi & $30.8 \pm 5.0$ & $2849.3 \pm 0.3$ & Undefined & $62.9 \pm 1.1$ & $63.2 \pm 0.1$
\end{tabular}

Lower OR-HEX Phase Transition Temperature. The lateral organization and conformational ordering of the lipids in the healthy and diseased skin models were examined using FTIR. Information about the conformational ordering and packing of lipid chains are provided by the $\nu_{\mathrm{s}} \mathrm{CH}_{2}$ and $\delta \mathrm{CH}_{2}$ frequencies, respectively. Low $\nu_{\mathrm{s}} \mathrm{CH}_{2}$ frequency below 2850 $\mathrm{cm}^{-1}$ is characteristic of highly ordered hydrocarbon chains typically packed either in the orthorhombic or hexagonal lateral phase. The thermotropic response of the $\nu_{\mathrm{s}} \mathrm{CH}_{2}$ mode in the healthy and diseased skin models are presented in Figure 4. The average $\nu_{\mathrm{s}} \mathrm{CH}_{2}$ frequencies for the various models at $10{ }^{\circ} \mathrm{C}$ are presented in Table 3. Dis-Combi exhibits the highest wavenumber indicating a lower conformation ordering compared to the other models. However, the difference was not significant. As the temperature increases, an approximate 1 $\mathrm{cm}^{-1}$ rise in the wavenumber occurs between 20 and $40{ }^{\circ} \mathrm{C}$ indicative of an OR-HEX phase transition. The midpoint temperatures of the OR-HEX phase transition $\left(T_{\mathrm{M}, \mathrm{OR}-\mathrm{HEX}}\right)$ are presented in Table 3. The $T_{\mathrm{M}, \mathrm{OR}-\mathrm{HEX}}$ of Dis-FFA $\mathrm{Ch}_{\mathrm{ch}}$ is significantly lower than that of the healthy skin model. The $T_{\mathrm{M}, \mathrm{OR}-\mathrm{HEX}}$ of Dis-Combi was not defined indicating that the lipid chains were primarily in the hexagonal phase at the initial temperature.

3.5. Increased Level of Short-Chain FFAs Induced Hexagonal Lateral Packing at Physiological Temperature. In addition to the $\rho \mathrm{CH}_{2}$ mode, the $\delta \mathrm{CH}_{2}$ and $\delta \mathrm{CD}_{2}$ modes are affected by the packing arrangements in ordered phases. Broadening or splitting of the scissoring contour signifies an orthorhombic packing. In contrast, hexagonal packing is characterized by a single peak located at $\sim 1467$ $\mathrm{cm}^{-1}$. The thermotropic response of the $\delta \mathrm{CH}_{2}$ frequencies is provided in Figure 5. The contour of the $\delta \mathrm{CH}_{2}$ modes of the healthy skin model at $10{ }^{\circ} \mathrm{C}$ is split into a strong doublet located at $\sim 1462$ and $1473 \mathrm{~cm}^{-1}$ indicating orthorhombic lateral packing. At $32{ }^{\circ} \mathrm{C}$, the $\delta \mathrm{CH}_{2}$ mode of the healthy skin model displayed a weaker doublet with a peak shift in the lower frequency component to $\sim 1467 \mathrm{~cm}^{-1}$ indicating a coexistence with a hexagonal phase. A similar profile was observed in the $\delta \mathrm{CH}_{2}$ modes of Dis- $\mathrm{CER}_{\mathrm{ch}}$ and Dis-CER $\mathrm{CL}_{\mathrm{ch}-\mathrm{sbC}}$. In contrast, the $\delta \mathrm{CH}_{2}$ mode of Dis $\mathrm{FFA}_{\text {ch }}$ displayed a weak doublet at $10{ }^{\circ} \mathrm{C}$ indicating a substantially lower proportion of lipids in an orthorhombic phase already at low temperatures. The $\delta \mathrm{CH}_{2}$ mode of Dis-combi at $10{ }^{\circ} \mathrm{C}$ displays a strong central peak located at $\sim 1467 \mathrm{~cm}^{-1}$ and a weak peak at $\sim 1473$ $\mathrm{cm}^{-1}$ showing that the lipids form predominantly a hexagonal phase. At $32{ }^{\circ} \mathrm{C}$,the $\delta \mathrm{CH}_{2}$ modes of Dis $\mathrm{FFA}_{\mathrm{ch}}$ and Dis-combi display a single peak at $\sim 1467 \mathrm{~cm}^{-1}$ indicating that the lipids exist predominantly in the hexagonal phase.

3.6. Changes in CER Composition Reduced the Mixing of CERs and FFAs at Low Temperature. By substituting the FFAs with their deuterated counterparts, the phase transition of the CER and DFFA chains can be monitored simultaneously since the frequencies of vibrational modes of protonated and deuterated acyl chains appear at different positions in the IR spectrum. The $T_{\text {M,HEX-LIQ }}$ of the $\nu_{\mathrm{s}} \mathrm{CH}_{2}$ and $\nu_{\mathrm{s}} \mathrm{CD}_{2}$ modes are presented in Table 3 . In all the models, the CERs and DFFA chains melted in the same temperature range (not shown) indicating the mixing of the 

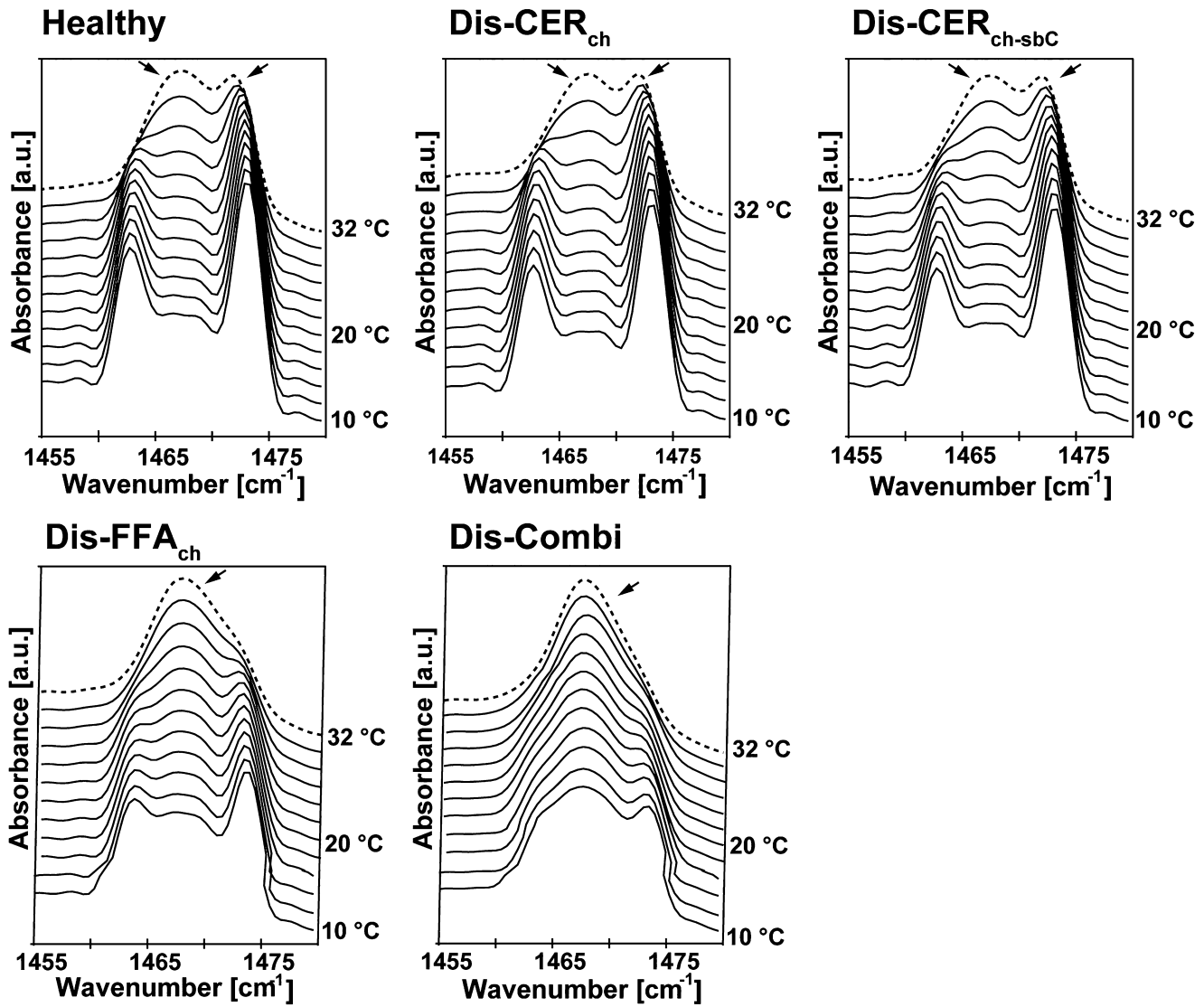

Figure 5. Thermotropic response of the $\delta \mathrm{CH}_{2}$ modes of the healthy and diseased skin models. At $32{ }^{\circ} \mathrm{C}$, the modes of Healthy, Dis-CER

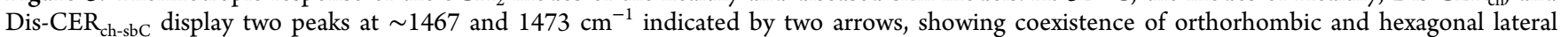
packing while those of Dis-FFA $\mathrm{ch}$ and Dis-combi display a single peak located at $\sim 1467 \mathrm{~cm}^{-1}$ indicated by single arrows representing hexagonal phase.

CER and DFFA chains. To obtain detailed information on the mixing of protiated and deuterated chains, we examined the $\delta \mathrm{CH}_{2}$ and $\delta \mathrm{CD}_{2}$ modes. When CER and DFFA chains mix in the same orthorhombic lattice and are thus adjacent to each other, the $\delta \mathrm{CH}_{2}$ and $\delta \mathrm{CD}_{2}$ vibrational frequencies are sufficiently different in energy to preclude the short-range vibrational coupling between the chains thereby precluding the mode splitting characteristic of orthorhombic packing. Consequently, only a single peak is observed in the $\delta \mathrm{CH}_{2}$ and $\delta \mathrm{CD}_{2}$ modes. The $\delta \mathrm{CD}_{2}$ modes of the healthy and diseased skin models are displayed in Figure 6. At $10{ }^{\circ} \mathrm{C}$, the $\delta \mathrm{CD}_{2}$ mode from the DFFAs in D-Healthy, D-Dis-CER $\mathrm{Ch}_{\mathrm{ch}}$ and

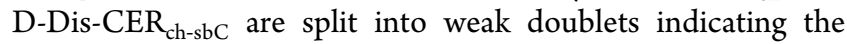
coupling of adjacent DFFA chains. A fraction of the DFFA chains were still able to interact as they are located at neighboring positions in the orthorhombic lattice. ${ }^{37}$ The magnitude of the band splitting is indicative of the degree of interchain interactions and of the size of the domains with an orthorhombic organization. ${ }^{12,36,38}$ The splitting values in the $\delta \mathrm{CD}_{2}$ mode of the samples were $3.1 \pm 0.2,3.5 \pm 0.2$, and $4.2 \pm$ $0.5 \mathrm{~cm}^{-1}$ for D-Healthy, D-Dis-CER $\mathrm{ch}_{\mathrm{ch}}$ and D-Dis-CER $\mathrm{Ch}_{\mathrm{cbc}}$, respectively. The mixing of the CERs and DFFA chains was more enhanced in the healthy model compared with the diseased skin models as indicated by the lower splitting value and shallower minima between the $\delta \mathrm{CD}_{2}$ peaks in the spectrum. D-Dis-CER $\mathrm{ch}_{\text {-sbC }}$ exhibited the highest splitting value and deepest minima between the $\delta \mathrm{CD}_{2}$ peaks indicating the most $\mathrm{CD}_{2}-\mathrm{CD}_{2}$ interaction. Upon further increase in temperature, the splitting collapses into single peaks in all the models at $\sim 25{ }^{\circ} \mathrm{C}$ resulting from a combined effect of the mixing of the CERs and DFFA chains and transition to the hexagonal phase. The $\delta \mathrm{CD}_{2}$ modes of D-Dis-FFA $\mathrm{A}_{\mathrm{ch}}$ and Discombi at $10{ }^{\circ} \mathrm{C}$ exhibit a single central peak since the chains pack predominantly in a hexagonal phase as shown in the corresponding protonated mixtures.

3.7. Short-Chain CERs Present in Diseased Models Are Less Ordered than the Physiological Chain Length CERs. Another application of selective lipid deuteration is monitoring the individual acyl chain of CER NS conformational ordering in the $\nu_{\mathrm{s}} \mathrm{CD}_{2}$ mode of mixtures. For these measurements, the deuterated acyl chain in either CER NS (C16) or CER NS (C24) in the Dis-CER selected. We compared the conformational ordering of the long and short chains in Dis $\mathrm{CER}_{\mathrm{ch}}$. The compositions of both models are presented in Table 1 , and their $\nu_{\mathrm{s}} \mathrm{CD}_{2}$ wavenumbers are shown in Figure 7. The $\nu_{s} \mathrm{CD}_{2}$ wavenumber of

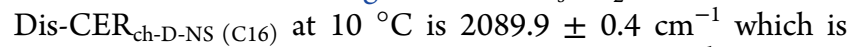
significantly higher than $2088.4 \pm 0.04 \mathrm{~cm}^{-1}$ in Dis$\mathrm{CER}_{\text {ch-D-NS (C24) }}(\mathrm{n}=3, p<0.01)$ indicating lower conformational ordering in the former.

3.8. Changes in CER Composition Affects the Lamellar Organization in Skin Lipid Models. The influence of the changes in lipid composition in the diseased model on the lamellar organization was examined by SAXD. The SAXD profile of the healthy skin model is shown earlier in Figure $2 \mathrm{~A}$ while those of the diseased models are provided in 

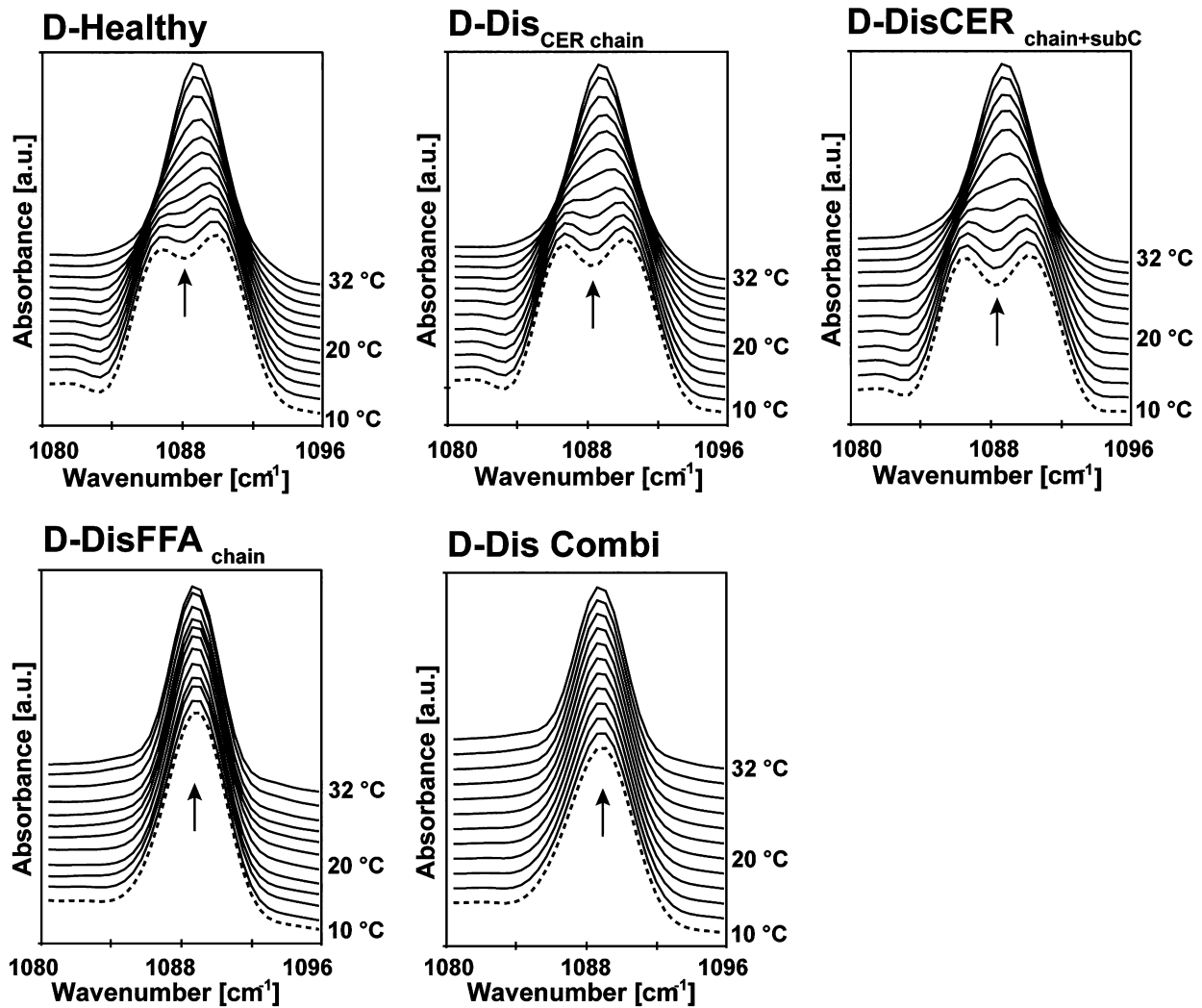

Figure 6. $\delta \mathrm{CD}_{2}$ modes of the lipid models. D-Dis-CER ${ }_{\mathrm{ch}-\mathrm{sbC}} \delta \mathrm{CD}_{2}$ mode doublets displayed the deepest minima at $10{ }^{\circ} \mathrm{C}$ when compared with $\mathrm{D}$ Dis-CER $_{c h}$ and D-Healthy indicating the greatest interaction between DFFA chains in the former, while D-Dis-FFA single peaks since the chains pack predominantly in a hexagonal phase.

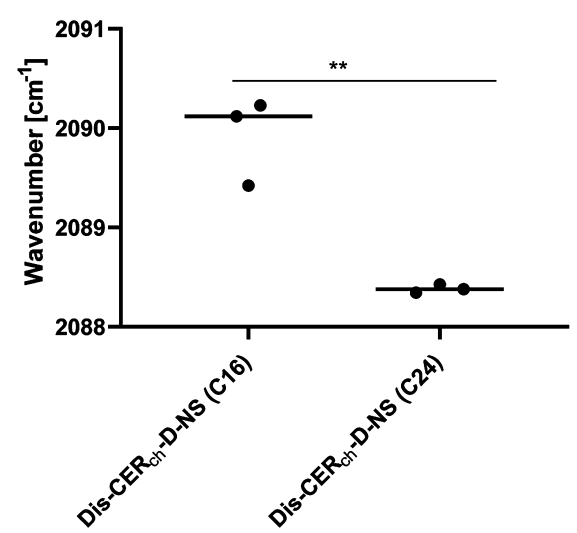

Figure 7. $\nu_{\mathrm{s}} \mathrm{CD}_{2}$ wavenumber at $10{ }^{\circ} \mathrm{C}$. The average peak position of the $\mathrm{v}_{\mathrm{s}} \mathrm{CD}_{2}$ curve for Dis-CER ch-D-NS (C16) and Dis-CER Dis-CER ch-D-NS (C16) wavenumber is significantly higher than that of

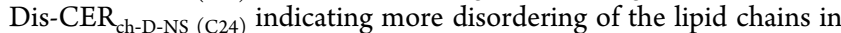
the former, $n=3, * * p<0.01$.

Figure 8. Both the healthy and the diseased skin models revealed a number of diffraction peaks attributed to the LPP and the SPP with repeat distances of $\sim 12.8$ and $5.4 \mathrm{~nm}$, respectively. The diffraction pattern of Dis-CER ch $_{\text {displayed an }}$ extra peak at $q=1.5 \mathrm{~nm}^{-1}$ that did not match the spacing of either the LPP or SPP, suggesting the presence of an additional phase. When focusing on Dis-CER $\mathrm{ch}_{\mathrm{chbC}}$, the LPP formation was drastically reduced compared to the healthy skin model. Meanwhile, the diffraction pattern of Dis $\mathrm{FFA}_{\mathrm{ch}}$ did not markedly differ from that of Dis $\mathrm{CER}_{\mathrm{ch}}$. The diffraction pattern of Dis-combi was similar to that of the DisCER $_{\text {ch-sbC }}$ model aside from an extra peak at $q=1.3 \mathrm{~nm}^{-1}$ in the diffraction profile of the former. All the SAXD profiles studied revealed the presence of a peak related to a spacing of $3.4 \mathrm{~nm}$ attributed to crystalline domains of phase-separated CHOL.

In addition to the lamellar organization, X-ray diffraction provides information about the lateral packing of lipid chains. Hexagonal lateral packing is characterized by a single $\sim 0.41$ $\mathrm{nm}$ peak, while orthorhombic packing is characterized by two peaks at $\sim 0.41$ and $\sim 0.37 \mathrm{~nm}$. We examined the changes in lamellar and lateral lipid organization simultaneously. A temperature range from 25 to $85^{\circ} \mathrm{C}$ was chosen. We selected three models: Healthy, along with Dis-CER $\mathrm{Ch}_{\text {ch-sc }}$ and DisFFA $_{c h}$, which exhibited pronounced alterations in the lamellar and lateral lipid organization, respectively. Sequential SAXD and WAXD plots as a function of temperature are presented in Figure 9A,B, respectively, while a summary of the phase changes in the various models is provided in Table 4. In all three models, the SPP is generally more thermostable than the LPP and the collapse of the SPP coincides with the disappearance of the hexagonal phase. Focusing on the WAXD profile, the intensity of the $0.41 \mathrm{~nm}$ peak in the models decreases with increasing temperature and shifts slightly to the right before finally disappearing, marking the collapse of the hexagonal phase. Dis-CER $\mathrm{Ch}_{\mathrm{cbc}} \mathrm{LPP}$ was the

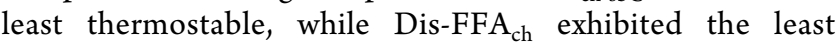
thermostable orthorhombic and hexagonal phases. In the SAXD profile, the $3.4 \mathrm{~nm}$ reflections attributed to CHOL also disappear at 70,60 , and $57{ }^{\circ} \mathrm{C}$ in Healthy, Dis-CER $\mathrm{Ch}_{\text {chsbC, and }}$ Dis-FFA $_{\mathrm{ch}}$, respectively. After the disappearance of the CHOL peaks, a broad $3.4 \mathrm{~nm}$ peak indicated by \# appeared in the 

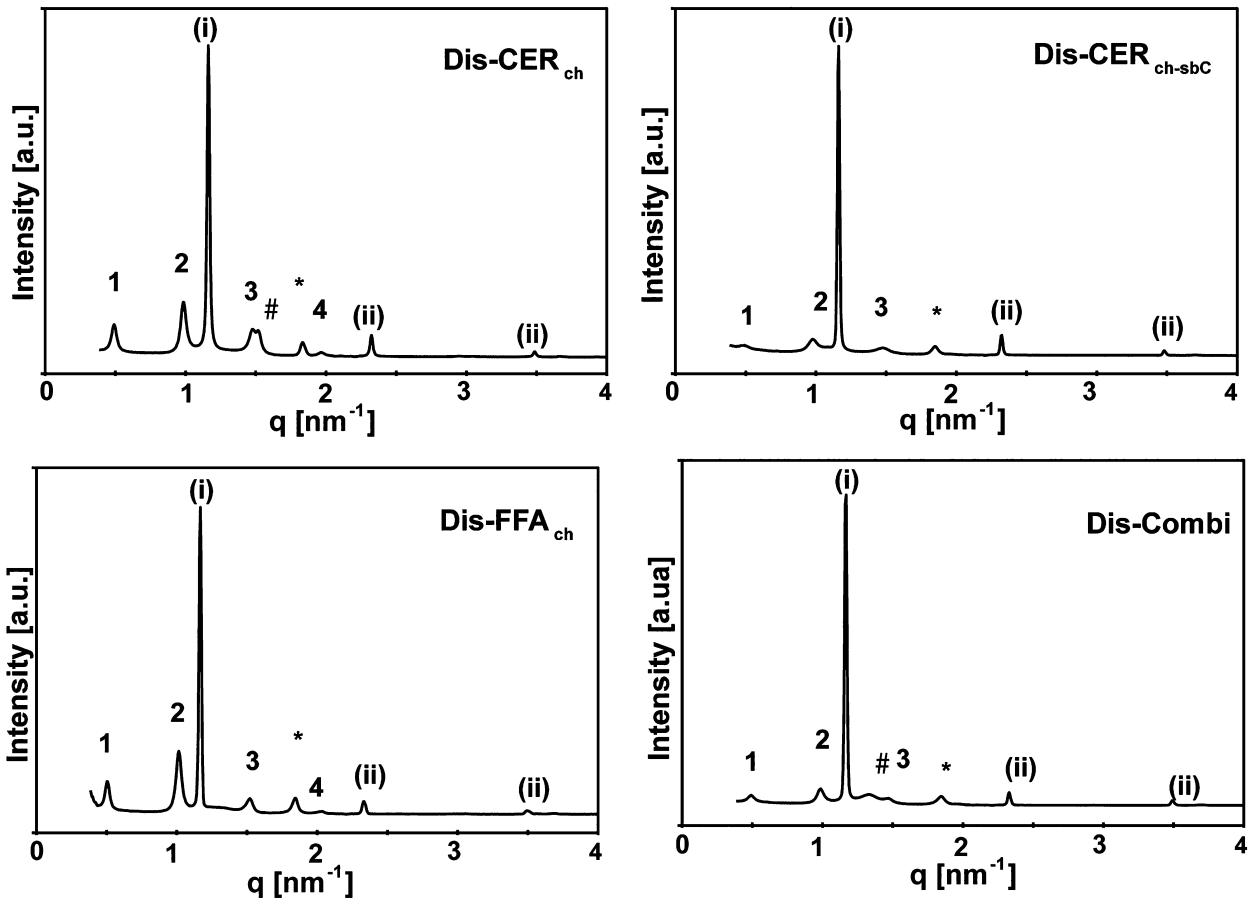

Figure 8. SAXD profile of the diseased skin models at $25{ }^{\circ} \mathrm{C}$. The arabic numbers $(1,2,3,4)$ indicate the first, second, third, and fourth order diffraction peaks of the LPP, respectively, while the roman numbers (i, ii, iii) indicate the diffraction orders of the SPP. In the diffraction profile of

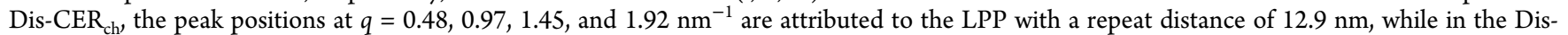
$\mathrm{CER}_{\text {ch-sbC }}$ diffraction profile, the peak positions at $q=0.49,0.98$, and $1.47 \mathrm{~nm}^{-1}$ are attributed to the LPP with a repeat distance of $12.8 \mathrm{~nm}$. In the diffraction pattern of Dis $\mathrm{FFA}_{\mathrm{ch}}$, the reflections at $q=0.49,0.99,1.48$, and $1.96 \mathrm{~nm}^{-1}$ are attributed to the LPP with a repeat distance of $12.7 \mathrm{~nm}$. Finally, the Dis-Combi diffraction profile is characterized by a series of sequential peaks positioned at $q=0.48,0.97$, and $1.47 \mathrm{~nm}^{-1}$ attributed to the LPP with a repeat distance of $12.9 \mathrm{~nm}$. In addition, an extra peak indicated by \# is located at $q=1.3$. In all the models, the series of diffraction peaks positioned at $q=1.16,2.3$, and $3.48 \mathrm{~nm}^{-1}$ indicate the first, second, and third diffraction orders attributed to the SPP with a repeat distance of $5.4 \mathrm{~nm}$ and the peaks attributed to crystalline CHOL located at $\mathrm{q}=1.83 \mathrm{~nm}^{-1}$ are indicated by an asterisk $(*)$.

models, shifting to lower $q$-values and increasing in intensity with increasing temperature, remaining present until $85^{\circ} \mathrm{C}$.

\section{DISCUSSION}

Though several studies have reported the association of filaggrin deficiency with $\mathrm{AD}$ and ichthyosis vulgaris, ${ }^{39-43}$ the role of filaggrin gene mutation in the barrier function impairment of $\mathrm{AD}$ patients remains contentious, ${ }^{16,21,44}$ suggesting that other factors also play a role. Some studies have reported a strong correlation between altered lipid composition and TEWL in the skin of $\mathrm{AD}$ patients. ${ }^{22,25,45}$ As CERs and FFAs have a common synthetic pathway, ${ }^{46,47}$ changes in their compositions were observed simultaneously in $\mathrm{AD}$ patients' skin including reduction in chain length of CERs and FFAs and changes in CER subclass composition. However, it is not yet known which changes in the lipid composition impact most the skin barrier in $\mathrm{AD}$, as multiple compositional changes occur simultaneously. Therefore, we have investigated the contributions of various abnormalities common to the lipid matrix of $\mathrm{AD}$ patients' skin using model membrane systems. This allows us to systematically study the impact of each of these changes on the lipid barrier. ${ }^{48}$

For a model membrane to be used as a substitute for the native skin, preferably, the lipid composition and organization should be similar. In the present study, we developed a model membrane mimicking the CER composition of human SC as closely as possible taking into account the commercially available synthetic CER subclasses. A previous study from our group employed a model based on pig CER composition because most of the CER subclasses in pig skin were available when the model was developed. ${ }^{34}$ The pig CER model differs from the human CER model by the presence of short-chain CERs (particularly CER NP (C16)) and the presence of an abundant amount of CER NS at the expense of the more hydrophilic subclasses. When comparing the human lipid model with that of the previous pig CER model, there was hardly any difference in the lipid organization in the models. In both models, the lipids were assembled in the two characteristic lamellar phases and adopted orthorhombic lateral packing. However, the LPP repeat distance was slightly longer in the human CER model, which closely resembled that of the native human skin.

4.1. Changes in the CER Profile Altered the Lamellar Organization in Model SC. Changes in the CER subclass distribution as well as a reduction in the chain length occur in the skin of $\mathrm{AD}$ patients. In a previous report, the level of CER NS (C16) was shown to correlate strongly with the TEWL values in $\mathrm{AD}$ patients' skin. ${ }^{22}$ Subsequently, an excellent correlation was demonstrated between CER chain length reduction and barrier function impairment in $\mathrm{AD}$ patients. ${ }^{25}$ In the current study, we show that the inclusion of CERs $\mathrm{NS}(\mathrm{C} 16)$ and AS (C16) in the SC model membrane (Dis$\mathrm{CER}_{\mathrm{ch}}$ ) results in a slightly higher permeability compared to that of the healthy skin model. By selective deuteration of either the C16 fatty acid acyl chain of CER NS (C16) or the C24 fatty acid acyl chain of CER NS (C24) in Dis-CER ch , we demonstrated that shorter chain length CERs are less conformationally ordered than the long physiological acyl 

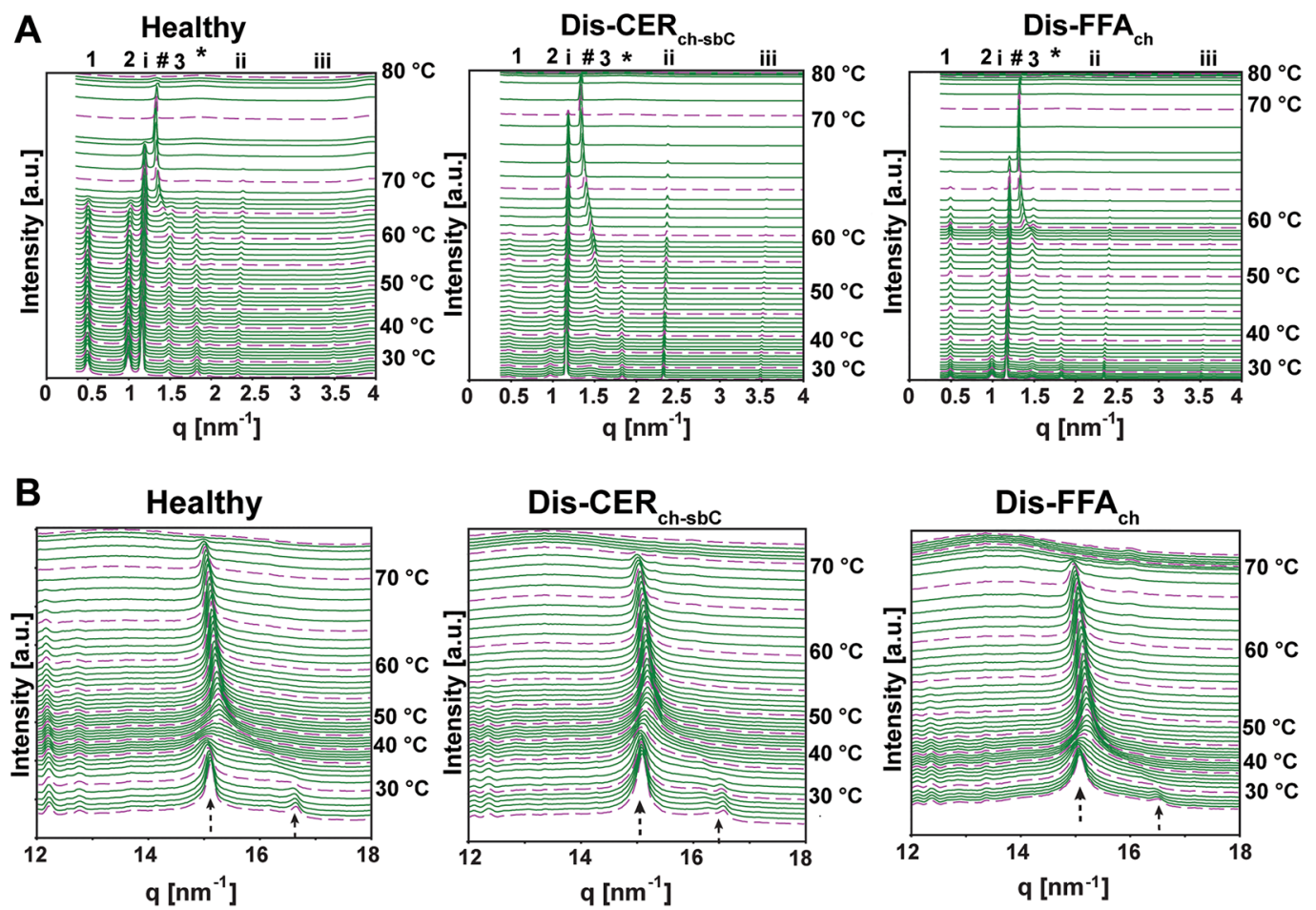

Figure 9. X-ray diffraction profile of the healthy and diseased skin lipid models 25 to $85^{\circ} \mathrm{C}$. (A) SAXD profile showing the changes in the lamellar organization with increasing temperature. The arabic numbers $(1,2,3)$ indicate the diffraction orders of the LPP. The roman numbers (i, ii, iii) indicate the diffraction orders of the SPP. The symbols * and \# indicate phase-separated CHOL and an additional phase, respectively. (B) WAXD showing the changes in the lateral packing with increasing temperature. The arrows show the 0.41 and $0.37 \mathrm{~nm}$ peaks located at $q=\sim 15.20$ and $16.7 \mathrm{~nm}^{-1}$, respectively.

Table 4. Summary of Phase Changes on Temperature Increase

\begin{tabular}{lcccc} 
& \multicolumn{4}{c}{ Temperature at } \\
\cline { 2 - 5 } \multicolumn{1}{c}{ Model } & LPP & SPP & OR phase & HEX phase \\
Healthy & 70 & 74 & 38 & 74 \\
Dis-CER $_{\text {ch-sbC }}$ & 63 & 72 & 37 & 71 \\
Dis-FFA $_{\text {ch }}$ & 68 & 68 & 33 & 68 \\
\hline
\end{tabular}

chain length CERs. This is a plausible explanation for the slight increase in the permeability of Dis-CER $\mathrm{Ch}_{\text {ch }}$ compared to that of the healthy skin model. Previous studies reported significantly higher permeabilities in model membranes with the CER fraction made up of short-chain length CERs with fatty acid acyl chain length $\mathrm{C} 4-\mathrm{C} 8$ as opposed to physiological chain length CERs. ${ }^{49,50}$ While the substitution of CER NS/AS (C24) in the healthy skin model by their C16 CER counterparts in Dis-CER $\mathrm{Ch}_{\mathrm{ch}}$ is substantial, the permeability difference between the models was not significant. This indicates that although a strong correlation was observed between the skin barrier and the presence of CER NS (C16) in the clinical studies, this might not be the prime underlying factor for an impaired skin barrier.

For a comprehensive representation of the CER profile of $\mathrm{AD}$ patients, we made additional changes in CER composition, thereby mimicking the CER subclass composition more closely as found in the $\mathrm{SC}$ of $\mathrm{AD}$ patients. The levels of sphingosine based CERs AS and NS were increased at the expense of CER $\mathrm{NP}$ and CER EOS fractions. These simultaneous changes in the CER chain length and subclass (Dis-CER $\mathrm{Ch}_{\mathrm{cbC}}$ ) resulted in a further increase in permeability, but was not yet significant. The compositional change resulted in a drastic reduction of the lipid fraction forming the LPP, mainly attributed to the reduction in CER EOS level as reported in literature. For instance, in a lipid mixture based on human isolated CERs, predominantly, the SPP was formed at the expense of the LPP when CER EOS was excluded from the mixture. ${ }^{51}$ In addition, model mixtures based on synthetic lipids formed exclusively the short phase when CER EOS was excluded and showed a reduced lipid barrier. ${ }^{52-55}$ Furthermore, a reduced level of CER NP is also expected to contribute to a reduced lipid barrier; recently it was reported that a higher permeability was observed in sphingosine based CERs membranes in comparison to their phytosphingosine counterparts. ${ }^{33}$ Although a further increase in permeability was observed, our results indicated that a change in ceramide subclass composition is not a major underlying factor for the increased permeability of the skin in $\mathrm{AD}$ patients.

4.2. Increased Level of Short Chain Length FFAs Reduced the Packing Density and Conformational Ordering in Model SC. While maintaining the CER composition of the healthy skin, an increased fraction of short-chain FFAs (Dis-FFA $A_{\text {ch }}$ ), as reported in lesional skin of $\mathrm{AD}$ patients, ${ }^{26}$ resulted in a significant increase in permeability compared with the healthy skin model and the changes in permeability were more pronounced than those induced by the changes in CER profile. By calculating the average carbon chain length in the diseased skin models relative to that the healthy skin model, we deduced that increased levels of short chain FFAs (mostly C16 and C18) decreased the average FFA chain length by 2.4 carbon atoms in Dis-FFA $\mathrm{A}_{\mathrm{ch}}$, while increased levels of CERs NS and AS (C16) at the expense of their C24 counterparts resulted in a 1.0 carbon atom reduction in Dis$\mathrm{CER}_{\text {ch. }}$ Interestingly, a greater reduction in carbon atoms (3.8) 
was obtained in Dis-CER $\mathrm{Ch}_{\mathrm{cb} \text {, }}$, attributed to the reduced concentration of the exceptionally long CER EOS. The compositional changes in CERs composition had more consequences on the carbon chain length than compositional changes in the FFAs, and therefore the FFAs did not have a stronger reduction in chain length that could account for the higher impact on the barrier function.

In a previous study, it was shown that shorter FFA chain lengths resulted in an increased conformational disordering and a reduced barrier, ${ }^{56}$ but in addition to this change in conformational ordering, the reduction in FFA chain length in the present study resulted also in a reduced lipid fraction assembled in the orthorhombic phase. This change in lateral packing was not observed by reducing the average chain length of the CERs and may therefore explain the higher permeability in the Dis-FFA ${ }_{\text {ch }}$ model. Our results agree with those of previous studies that reported an increased permeability of model membranes as a consequence of reduced packing density. ${ }^{34,57}$ A reduced lateral packing density was also observed in $\mathrm{AD}$ skin in comparison with healthy skin model and may be caused by the shorter FFA rather the shorter CER chains in $\mathrm{AD} .^{25,58,24}$ Thus, the reduction in FFA chain length can result in the reduced conformational ordering of lipid chains observed in $\mathrm{AD}$ patients' skin, compared to the healthy skin model. ${ }^{25}$

There was extensive mixing of the CER and FFA chains in the models studied since no domains of phase-separated FFA were identified in the $\delta \mathrm{CD}_{2}$ modes of the models. As previously reported, the $\delta \mathrm{CD}_{2}$ of the pure DFFA mixture is characterized by large splitting, measuring $7.2 \mathrm{~cm}^{-1}$ and remaining present until $72{ }^{\circ} \mathrm{C} .{ }^{33}$ The introduction of $\mathrm{C} 16$ acyl chain length CERs NS and AS in D-DIS CER ch $_{\text {resulted in }}$ slightly less miscibility of the CER and FFA chains compared to the healthy skin model at low temperature indicated by the slight increase in splitting value of the $\delta \mathrm{CD}_{2}$ mode. Further increase in splitting value was recorded after modulations in the CER subclass fractions. Our data suggest that a lower level of CER EOS may reduce the miscibility of CERs and FFA as we observed that the absence of CER EOS reduced the miscibility of CERs and FFAs (unpublished work).

Previous FTIR studies of ternary SC model mixtures (CER NS (C24)/CHOL/FFA (C16) or (C24)) reported phase separation when FFA (C16) was incorporated into the SC model mixture and was homogeneously mixed on the incorporation of $\mathrm{C} 24$ chain length FFA. ${ }^{35,59,60}$ Separate domains of FFA occurred in CER NS (C24)/CHOL/FFA (C16) as the short-chain length FFA did not fit with the longchain CER. The reason for the extensive mixing of the CERs and FFA chains in D-DIS $\mathrm{CER}_{\mathrm{ch}}$ irrespective of the introduction of short-chain length CERs may be the variety in FFA chain lengths in the present mixture. Despite the simultaneous reduction of CER EOS in Dis-CER $\mathrm{Ch}_{\text {ch-sc }}$, CER C16 still fitted in the lamellar structure. This is evident by the absence of phase-separated CER in the $\mathrm{CH}_{2}$ mode of D-Dis$\mathrm{CER}_{\text {ch-sbC }}$ (not shown). The absence of phase separation was also reported in complex SC models containing CER (C24)/ CHOL/FFAs (C16-C24) and our pig SC models. ${ }^{35,61} \mathrm{~A}$ previous study reported that such FFA chain length distribution in the SC may be required for the coexistence of a proportion of solid lipids and fluid domains, which is suggested to be important for normal skin barrier function. ${ }^{62}$ Complex SC model mixtures with a variety of CER subclasses and FFAs chain length, as employed in the current study, appear to be resilient to phase separation even when the levels of short acyl chain lengths are increased. CER headgroup diversity and FFA chain length distribution may provide robustness to the barrier that is necessary for withstanding challenges in the environment.

\section{SUMMARY AND CONCLUSIONS}

The changes in the lipid compositions of model membranes that mimic the changes observed in $\mathrm{AD}$ patients resulted in a reduced barrier capability. Modulations in CER composition altered the lamellar organization, while changes in FFAs composition induced the phase transition from the dense orthorhombic to the less dense hexagonal packing. The present study shows that FFA compositional changes in $\mathrm{AD}$ skin have a greater impact on the barrier function than changes in the CER profile, most likely due to a change in packing density, which does not occur when shortening the CER chain length. These findings are highly suggestive that $\mathrm{AD}$ therapies that target the normalization of the FFA composition are at least as important as those that target the normalization of CER composition.

\section{AUTHOR INFORMATION}

\section{Corresponding Author}

*Tel: 003171527 4208. Fax: 003171527 4565. E-mail: bouwstra@chem.leidenuniv.nl.

ORCID $\odot$

Joke.A. Bouwstra: 0000-0002-7123-6868

Notes

The authors declare no competing financial interest.

\section{ACKNOWLEDGMENTS}

We are grateful to the company Evonik for the donation of CERs. We also acknowledge the staff at the DUBBLE beamline $26 \mathrm{~b}$ at the ESRF, Grenoble, France who assisted with the X-ray diffraction measurements.

\section{REFERENCES}

(1) Hannun, Y. A. Functions of ceramide in coordinating cellular responses to stress. Science 1996, 274 (5294), 1855-9.

(2) Brasaemle, D. L. Thematic review series: adipocyte biology. The perilipin family of structural lipid droplet proteins: stabilization of lipid droplets and control of lipolysis. J. Lipid Res. 2007, 48 (12), 2547-59.

(3) van Blitterswijk, W. J.; van der Luit, A. H.; Veldman, R. J.; Verheij, M.; Borst, J. Ceramide: second messenger or modulator of membrane structure and dynamics? Biochem. J. 2003, 369 (2), 199211.

(4) Wang, X. Lipid signaling. Curr. Opin. Plant Biol. 2004, 7 (3), $329-336$

(5) Quinn, P. J. Structure of sphingomyelin bilayers and complexes with cholesterol forming membrane rafts. Langmuir 2013, 29 (30), 9447-56.

(6) Gonzalez-Ramirez, E. J.; Artetxe, I.; Garcia-Arribas, A. B.; Goni, F. M.; Alonso, A. Homogeneous and heterogeneous bilayers of ternary lipid compositions containing equimolar ceramide and cholesterol. Langmuir 2019, 35 (15), 5305-5315.

(7) Weerheim, A.; Ponec, M. Determination of stratum corneum lipid profile by tape stripping in combination with high-performance thin-layer chromatography. Arch. Dermatol. Res. 2001, 293 (4), 191199.

(8) Mendelsohn, R.; Flach, C. R.; Moore, D. J. Determination of molecular conformation and permeation in skin via IR spectroscopy, microscopy, and imaging. Biochim. Biophys. Acta, Biomembr. 2006, 1758 (7), 923-933. 
(9) Bouwstra, J. A.; Gooris, G. S.; van der Spek, J. A.; Bras, W. Structural investigations of human stratum corneum by small-angle $\mathrm{X}$ ray scattering. J. Invest. Dermatol. 1991, 97 (6), 1005-12.

(10) White, S. H.; Mirejovsky, D.; King, G. I. Structure of lamellar lipid domains and corneocyte envelopes of murine stratum corneum. An X-ray diffraction study. Biochemistry 1988, 27 (10), 3725-32.

(11) Bouwstra, J.; Gooris, G.; Ponec, M. The lipid organisation of the skin barrier: Liquid and crystalline domains coexist in lamellar phases. J. Biol. Phys. 2002, 28 (2), 211-223.

(12) Boncheva, M.; Damien, F.; Normand, V. Molecular organization of the lipid matrix in intact stratum corneum using ATR-FTIR spectroscopy. Biochim. Biophys. Acta, Biomembr. 2008, 1778 (5), 1344-55.

(13) Norlen, L.; Nicander, I.; Lundsjo, A.; Cronholm, T.; Forslind, B. A new HPLC-based method for the quantitative analysis of inner stratum corneum lipids with special reference to the free fatty acid fraction. Arch. Dermatol. Res. 1998, 290 (9), 508-16.

(14) van Smeden, J.; Boiten, W. A.; Hankemeier, T.; Rissmann, R.; Bouwstra, J. A.; Vreeken, R. J. Combined LC/MS-platform for analysis of all major stratum corneum lipids, and the profiling of skin substitutes. Biochim. Biophys. Acta, Mol. Cell Biol. Lipids 2014, 1841 (1), 70-79.

(15) t'Kindt, R.; Jorge, L.; Dumont, E.; Couturon, P.; David, F.; Sandra, P.; Sandra, K. Profiling and characterizing skin ceramides using reversed-phase liquid chromatography-quadrupole time-offlight mass spectrometry. Anal. Chem. 2012, 84 (1), 403-411.

(16) van Smeden, J.; Bouwstra, J. A. Stratum corneum lipids: Their role for the skin barrier function in healthy subjects and atopic dermatitis patients. Curr. Probl. Dermatol. 2016, 49, 8-26.

(17) Wertz, P. W.; Miethke, M. C.; Long, S. A.; Strauss, J. S.; Downing, D. T. The composition of the ceramides from human stratum corneum and from comedones. J. Invest. Dermatol. 1985, 84 (5), 410-2.

(18) Motta, S.; Monti, M.; Sesana, S.; Caputo, R.; Carelli, S.; Ghidoni, R. Ceramide composition of the psoriatic scale. Biochim. Biophys. Acta, Mol. Basis Dis. 1993, 1182 (2), 147-51.

(19) Proksch, E.; Folster-Holst, R.; Jensen, J. M. Skin barrier function, epidermal proliferation and differentiation in eczema. $J$. Dermatol. Sci. 2006, 43 (3), 159-69.

(20) Jensen, J. M.; Folster-Holst, R.; Baranowsky, A.; Schunck, M.; Winoto-Morbach, S.; Neumann, C.; Schutze, S.; Proksch, E. Impaired sphingomyelinase activity and epidermal differentiation in atopic dermatitis. J. Invest. Dermatol. 2004, 122 (6), 1423-31.

(21) Jakasa, I.; Koster, E. S.; Calkoen, F.; Irwin McLean, W. H.; Campbell, L. E.; Bos, J. D.; Verberk, M. M.; Kezic, S. Skin Barrier Function in Healthy Subjects and Patients with Atopic Dermatitis in Relation to Filaggrin Loss-of-Function Mutations. J. Invest. Dermatol. 2011, 131 (2), 540-542.

(22) Ishikawa, J.; Narita, H.; Kondo, N.; Hotta, M.; Takagi, Y.; Masukawa, Y.; Kitahara, T.; Takema, Y.; Koyano, S.; Yamazaki, S.; Hatamochi, A. Changes in the ceramide profile of atopic dermatitis patients. J. Invest. Dermatol. 2010, 130 (10), 2511-4.

(23) Di Nardo, A.; Wertz, P.; Giannetti, A.; Seidenari, S. Ceramide and cholesterol composition of the skin of patients with atopic dermatitis. Acta Derm-Venereol. 1998, 78 (1), 27-30.

(24) Imokawa, G.; Abe, A.; Jin, K.; Higaki, Y.; Kawashima, M.; Hidano, A. Decreased level of ceramides in stratum corneum of atopic dermatitis: an etiologic factor in atopic dry skin? J. Invest. Dermatol. 1991, 96 (4), 523-6.

(25) Janssens, M.; van Smeden, J.; Gooris, G. S.; Bras, W.; Portale, G.; Caspers, P. J.; Vreeken, R. J.; Hankemeier, T.; Kezic, S.; Wolterbeek, R.; Lavrijsen, A. P.; Bouwstra, J. A. Increase in shortchain ceramides correlates with an altered lipid organization and decreased barrier function in atopic eczema patients. J. Lipid Res. 2012, 53 (12), 2755-66.

(26) van Smeden, J.; Janssens, M.; Kaye, E. C.; Caspers, P. J.; Lavrijsen, A. P.; Vreeken, R. J.; Bouwstra, J. A. The importance of free fatty acid chain length for the skin barrier function in atopic eczema patients. Exp. Dermatol. 2014, 23 (1), 45-52.
(27) Elias, P. M. Primary role of barrier dysfunction in the pathogenesis of atopic dermatitis. Exp. Dermatol. 2018, 27 (8), 847851.

(28) Cork, M. J.; Danby, S. G.; Vasilopoulos, Y.; Hadgraft, J.; Lane, M. E.; Moustafa, M.; Guy, R. H.; MacGowan, A. L.; Tazi-Ahnini, R.; Ward, S. J. Epidermal Barrier Dysfunction in Atopic Dermatitis. J. Invest. Dermatol. 2009, 129 (8), 1892-1908.

(29) Downing, P. W. W. a. D. T. Physiology, Biochemistry and molecular Biology of the skin. second ed., Oxford University Press: New York, 1991; Vol. 1, p 205-236.

(30) Schmitt, T.; Lange, S.; Sonnenberger, S.; Dobner, B.; Demé, B.; Neubert, R. H. H.; Gooris, G.; Bouwstra, J. A. Determination of the influence of $\mathrm{C} 24 \mathrm{D} /(2 \mathrm{R})$ - and $\mathrm{L} /(2 \mathrm{~S})$-isomers of the CER[AP] on the lamellar structure of stratum corneum model systems using neutron diffraction. Chem. Phys. Lipids 2017, 209, 29-36.

(31) International Conference on Harmonization (ICH) Q2 (R1), Validation of analytical procedures: Text and Methodology. 2005.

(32) European Pharmacopoeia. 8 ed., European directorate for the quality of medicines \& healthcare: Strasbourg, 2014; Vol. 1.

(33) Uche, L. E.; Gooris, G. S.; Beddoes, C. M.; Bouwstra, J. A. New insight into phase behavior and permeability of skin lipid models based on sphingosine and phytosphingosine ceramides. Biochim. Biophys. Acta, Biomembr. 2019, 1861 (7), 1317-1328.

(34) Mojumdar, E. H.; Helder, R. W.; Gooris, G. S.; Bouwstra, J. A. Monounsaturated fatty acids reduce the barrier of stratum corneum lipid membranes by enhancing the formation of a hexagonal lateral packing. Langmuir 2014, 30 (22), 6534-43.

(35) Oguri, M.; Gooris, G. S.; Bito, K.; Bouwstra, J. A. The effect of the chain length distribution of free fatty acids on the mixing properties of stratum corneum model membranes. Biochim. Biophys. Acta, Biomembr. 2014, 1838 (7), 1851-1861.

(36) Mendelsohn, R.; Liang, G. L.; Strauss, H. L.; Snyder, R. G. IR spectroscopic determination of gel state miscibility in long-chain phosphatidylcholine mixtures. Biophys. J. 1995, 69 (5), 1987-1998.

(37) Groen, D.; Gooris, G. S.; Bouwstra, J. A. Model membranes prepared with ceramide EOS, cholesterol and free fatty acids form a unique lamellar phase. Langmuir 2010, 26 (6), 4168-75.

(38) Snyder, R. G.; Goh, M. C.; Srivatsavoy, V. J. P.; Strauss, H. L.; Dorset, D. L. Measurement of the growth-kinetics of microdomains in binary $\mathrm{N}$-alkane solid-solutions by infrared-spectroscopy. J. Phys. Chem. 1992, 96 (24), 10008-10019.

(39) Rodriguez, E.; Illig, T.; Weidinger, S. Filaggrin loss-of-function mutations and association with allergic diseases. Pharmacogenomics 2008, 9 (4), 399-413.

(40) Gruber, R.; Elias, P. M.; Crumrine, D.; Lin, T. K.; Brandner, J. M.; Hachem, J. P.; Presland, R. B.; Fleckman, P.; Janecke, A. R.; Sandilands, A.; McLean, W. H.; Fritsch, P. O.; Mildner, M.; Tschachler, E.; Schmuth, M. Filaggrin genotype in ichthyosis vulgaris predicts abnormalities in epidermal structure and function. Am. J. Pathol. 2011, 178 (5), 2252-63.

(41) Irvine, A. D.; McLean, W. H.; Leung, D. Y. Filaggrin mutations associated with skin and allergic diseases. N. Engl. J. Med. 2011, 365 (14), 1315-27.

(42) Hudson, T. J. Skin barrier function and allergic risk. Nat. Genet. 2006, 38 (4), 399-400.

(43) McGrath, J. A. Filaggrin and the great epidermal barrier grief. Australas. J. Dermatol. 2008, 49 (2), 67-73.

(44) Danso, M.; Boiten, W.; van Drongelen, V.; Gmelig Meijling, K.; Gooris, G.; El Ghalbzouri, A.; Absalah, S.; Vreeken, R.; Kezic, S.; van Smeden, J.; Lavrijsen, S.; Bouwstra, J. Altered expression of epidermal lipid bio-synthesis enzymes in atopic dermatitis skin is accompanied by changes in stratum corneum lipid composition. J. Dermatol. Sci. 2017, 88 (1), 57-66.

(45) Janssens, M.; van Smeden, J.; Gooris, G. S.; Bras, W.; Portale, G.; Caspers, P. J.; Vreeken, R. J.; Kezic, S.; Lavrijsen, A. P.; Bouwstra, J. A. Lamellar lipid organization and ceramide composition in the stratum corneum of patients with atopic eczema. J. Invest. Dermatol. 2011, 131 (10), 2136-8. 
(46) van Smeden, J.; Janssens, M.; Boiten, W. A.; van Drongelen, V.; Furio, L.; Vreeken, R. J.; Hovnanian, A.; Bouwstra, J. A. Intercellular skin barrier lipid composition and organization in Netherton syndrome patients. J. Invest. Dermatol. 2014, 134 (5), 1238-1245.

(47) Kihara, A. Synthesis and degradation pathways, functions, and pathology of ceramides and epidermal acylceramides. Prog. Lipid Res. 2016, 63, 50-69.

(48) Kováčik, A.; Pullmannová, P.; Maixner, J.; Vávrová, K. Effects of ceramide and dihydroceramide stereochemistry at C-3 on the phase behavior and permeability of skin lipid membranes. Langmuir 2018, 34 (1), 521-529.

(49) Skolova, B.; Janusova, B.; Zbytovska, J.; Gooris, G.; Bouwstra, J.; Slepicka, P.; Berka, P.; Roh, J.; Palat, K.; Hrabalek, A.; Vavrova, K. Ceramides in the skin lipid membranes: length matters. Langmuir 2013, 29 (50), 15624-33.

(50) Janusova, B.; Zbytovska, J.; Lorenc, P.; Vavrysova, H.; Palat, K.; Hrabalek, A.; Vavrova, K. Effect of ceramide acyl chain length on skin permeability and thermotropic phase behavior of model stratum corneum lipid membranes. Biochim. Biophys. Acta, Mol. Cell Biol. Lipids 2011, 1811 (3), 129-37.

(51) Bouwstra, J. A.; Gooris, G. S.; Dubbelaar, F. E.; Ponec, M. Phase behavior of lipid mixtures based on human ceramides: coexistence of crystalline and liquid phases. J. Lipid Res. 1999, 42 (11), 1759-70.

(52) Groen, D.; Gooris, G. S.; Barlow, D. J.; Lawrence, M. J.; van Mechelen, J. B.; Deme, B.; Bouwstra, J. A. Disposition of ceramide in model lipid membranes determined by neutron diffraction. Biophys. J. 2011, 100 (6), 1481-1489.

(53) Mojumdar, E. H.; Groen, D.; Gooris, G. S.; Barlow, D. J.; Lawrence, M. J.; Deme, B.; Bouwstra, J. A. Localization of cholesterol and fatty acid in a model lipid membrane: a neutron diffraction approach. Biophys. J. 2013, 105 (4), 911-8.

(54) de Jager, M.; Groenink, W.; Bielsa i Guivernau, R.; Andersson, E.; Angelova, N.; Ponec, M.; Bouwstra, J. A novel in vitro percutaneous penetration model: evaluation of barrier properties with p-aminobenzoic acid and two of its derivatives. Pharm. Res. 2006, 23 (5), 951-60.

(55) Opalka, L.; Kovacik, A.; Maixner, J.; Vavrova, K. Omega-OAcylceramides in skin lipid membranes: effects of concentration, sphingoid base, and model complexity on microstructure and permeability. Langmuir 2016, 32 (48), 12894-12904.

(56) Uchiyama, M.; Oguri, M.; Mojumdar, E. H.; Gooris, G. S.; Bouwstra, J. A. Free fatty acids chain length distribution affects the permeability of skin lipid model membranes. Biochim. Biophys. Acta, Biomembr. 2016, 1858 (9), 2050-9.

(57) Skolova, B.; Jandovska, K.; Pullmannova, P.; Tesar, O.; Roh, J.; Hrabalek, A.; Vavrova, K. The role of the trans double bond in skin barrier sphingolipids: permeability and infrared spectroscopic study of model ceramide and dihydroceramide membranes. Langmuir 2014, 30 (19), 5527-35.

(58) Pilgram, G. S. K.; Vissers, D. C. J.; van der Meulen, H.; Koerten, H. K.; Pavel, S.; Lavrijsen, S. P. M.; Bouwstra, J. A. Aberrant lipid organization in stratum corneum of patients with atopic dermatitis and lamellar ichthyosis. J. Invest. Dermatol. 2001, 117 (3), 710-717.

(59) Paz Ramos, A.; Lafleur, M. Chain length of free fatty acids influences the phase behavior of stratum corneum model membranes. Langmuir 2015, 31 (42), 11621-11629.

(60) Skolova, B.; Hudska, K.; Pullmannova, P.; Kovacik, A.; Palat, K.; Roh, J.; Fleddermann, J.; Estrela-Lopis, I.; Vavrova, K. Different phase behavior and packing of ceramides with long (C16) and very long (C24) acyls in model membranes: infrared spectroscopy using deuterated lipids. J. Phys. Chem. B 2014, 118 (35), 10460-70.

(61) de Jager, M. W.; Gooris, G. S.; Ponec, M.; Bouwstra, J. A. Lipid mixtures prepared with well-defined synthetic ceramides closely mimic the unique stratum corneum lipid phase behavior. J. Lipid Res. 2005, 46 (12), 2649-2656.

(62) Chen, X.; Kwak, S.; Lafleur, M.; Bloom, M.; Kitson, N.; Thewalt, J. Fatty acids influence "solid" phase formation in models of stratum corneum intercellular membranes. Langmuir 2007, 23 (10), $5548-56$. 